\title{
PAISAJES MINERO-METALÚRGICOS INCAICOS EN ATACAMA Y EL ALTIPLANO SUR DE TARAPACÁ (NORTE DE CHILE)*
}

\author{
INKA MINING AND METALLURGICAL LANDSCAPES IN ATACAMA \\ AND SOUTHERN TARAPACA ALTIPLANO (NORTHERN CHILE)
}

\author{
Diego Salazar ${ }^{1}$, José Berenguer ${ }^{2}$ y Gabriela Vega ${ }^{3}$
}

\begin{abstract}
En el presente trabajo ponemos a prueba interpretaciones en boga que le otorgan a la actividad minera un rol central dentro del expansionismo incaico al norte de Chile, y en particular a la región atacameña y el altiplano sur de Tarapacá. Luego de sintetizar la información acerca de la minería en la región durante el Período Intermedio Tardío (ca. 950-1.400 d.C.), revisamos las evidencias arqueológicas de minería del cobre incaica en la región atacameña y el altiplano sur de Tarapacá (ca. 1.400-1.540 d.C.), reconstruyendo a partir de dicha revisión las modalidades de organización de la producción y su administración, así como el consecuente paisaje minero-metalúrgico instaurado por los Incas en la región. Concluimos señalando que no sólo la minería jugó un rol esencial dentro de la reorganización económica incaica en el área de estudio, sino que esta actividad y su simbolismo asociado fueron los ejes alrededor de los cuales el Tawantinsuyu reorganizó los espacios sociales y sagrados a nivel regional.
\end{abstract}

Palabras claves: producción minera, Tawantinsuyu, centros provinciales, paisaje minero-metalúrgico, norte de Chile.

The present paper examines current interpretations of the importance of mining activity in Inka expansion into northern Chile, and particularly into the Atacama and Southern Tarapacá regions. We first present a synthesis on the evidence for pre-inka and inka copper mining and metallurgy in the study area. We then go on to infer the organizational systems of production and administration of this activity during the Late Period (ca. 1,400-1,540 AD), and thus reconstruct the mining and metallurgical landscape created by Tawantinsuyu in Atacama and the southern altiplano of Tarapacá. We conclude that not only did copper mining play a major role in the reorganization of economic systems in the region, but that this activity and its symbolic context served as the principal axis of regional Inca social and sacred spaces.

Key words: Mining production, Tawantinsuyu, administrative and ceremonial sites, mining and metallurgical landscapes, northern Chile.

La cordillera de los Andes es una de las regiones más ricas del mundo en cuanto a su contenido y provisión de minerales metálicos y no metálicos, incluyendo grandes reservas de antimonio, cobre, estaño, nitratos, plata, platino, plomo y zinc, entre otros (Oyarzún 2000). Se ha estimado que casi el $50 \%$ de los recursos mundiales de cobre están alojados en las rocas del gran macizo andino, y una parte importante de esta enorme cantidad de reservas se concentra en tan sólo unos pocos yacimientos ubicados en el extremo norte de Chile, en particular entre las actuales Regiones I y III (Camus 2003).

El conocimiento de la riqueza mineral de este territorio no es un fenómeno reciente. Hoy sabemos que el cobre ya fue explotado como piedra semipreciosa desde el Arcaico Tardío en el norte de Chile (Núñez 2006; Salazar, Castro et al. 2010; Soto 2010), y que la minería del cobre se constituyó en una verdadera tradición tecnológica, económica y sociocultural al interior de las poblaciones agropastoriles atacameñas desde antes de la era cristiana (Rees 1999; Núñez 2006; Salazar y Salinas 2008).

Núñez (1999, 2006; Núñez et al. 2005) ha señalado que las prácticas mineras y metalúrgicas se hallaban bien establecidas en la región 2.500 años antes de los incas y que éstos aprovecharon la milenaria experticia atacameña en el laboreo de yacimientos minerales para incrementar la

\footnotetext{
* Artículo seleccionado del conjunto de ponencias presentadas en la Primera Reunión Internacional sobre Minería Prehispánica en América (PRIMPA), realizada en San Pedro de Atacama, Chile, diciembre 2010. Este manuscrito fue evaluado por investigadores externos y editado por Andrés Troncoso y Victoria Castro, Chile, en su calidad de editores invitados de la Revista.

1 Departamento de Antropología, Universidad de Chile, Santiago, Chile. dsalazar@uchile.cl

2 Museo Chileno de Arte Precolombino, Santiago, Chile. jberenguer@ museoprecolombino.cl

3 Guardia Vieja 12 Of. 44-Providencia, Santiago, Chile. gabri_una@yahoo.com
} 
producción de una variedad de metales y piedras semipreciosas, incluyendo cobre nativo, turquesa y diversos oxidados de cobre. Por su parte, ya en su seminal trabajo Llagostera (1976) planteaba para el norte de Chile la organización de un sistema agrominero bajo la administración incaica, que habría permitido la producción de cobre a gran escala a partir de la generación de excedentes agrícolas en los principales centros poblados de este territorio. En la actualidad, la mayoría de los arqueólogos sostiene que el móvil esencial de la ocupación Inca en la región fue explotar sus recursos mineros con el objeto de insertarlos dentro de la economía política estatal (Berenguer et al. 2005; Cornejo 1995; Niemeyer y Schiappacasse 1998 [1987]; Núñez 1999, 2006; Núñez et al. 2005; Raffino 1981; Salazar 2002, 2002-2005, entre otros).

No obstante lo anterior, puede afirmarse que son muy pocos los estudios acerca de las formas de organización de la producción minera Inca en la zona, las transformaciones operadas sobre los sistemas de producción preincaicos, o la articulación de las dinámicas productivas con el sistema económico y político instaurado por el Estado en las provincias. Una primera aproximación a esta temática desde el registro arqueológico ha podido realizarse en San José del Abra, donde se cuenta con contextos mineros incaicos y preincaicos bien datados y controlados (Núñez 1999; Salazar 2002, 2002-2005, 2008; Salazar y Salinas 2008; Salinas y Salazar 2008). Por otro lado, en el año 2010 los autores del presente artículo iniciaron un proyecto de investigación ${ }^{1}$ en las nacientes del río Loa, a los pies y al poniente del volcán Miño, cuyo propósito fundamental es investigar la existencia, naturaleza y organización funcional de las explotaciones minerometalúrgicas incaicas en el sector de Miño-Collahuasi desde una perspectiva "holística" (sensu Shimada 1994), estudiando la forma en que el Estado articuló las variables población, tecnología, infraestructura y recursos, dentro de su propio sistema económico. Ambas experiencias de investigación nos han permitido revaluar las evidencias de minería incaica en Atacama y el altiplano sur de Tarapacá (Figura 1) y nos han permitido reflexionar en torno a los paisajes productivos establecidos por el Estado en la zona.

Como fruto de dicha revaluación y reflexión, en el presente trabajo propondremos algunas consideraciones a nivel regional acerca de las modalidades bajo las cuales el Tawantinsuyu reorganizó la actividad minero-metalúrgica cuprífera local en las tierras altas de Atacama y el altiplano sur de Tarapacá, centrándonos en el concepto de paisaje productivo.

\section{Paisajes Minero-Metalúrgicos: Consideraciones Teóricas}

A nivel mundial, los minerales tienden a concentrarse en sectores alejados de los principales nodos de población y de producción agrícola de un territorio (Bell 1998; Ballard y Banks 2003). La región andina no fue una excepción a este respecto. Estos recursos de carácter estratégico suelen encontrarse con mayor frecuencia en los así llamados "espacios vacíos" (sensu Upham 1992), esto es, en aquellas extensas áreas intersticiales, muchas veces despobladas y por lo común montañosas, que separan a los principales nodos o centros poblados de una región (Angiorama 2001; Núñez 1987). Esta situación demandó en el pasado una compleja planificación e inversión para poder explotar y procesar los recursos minerales, lo que llevó a "colonizar" dichos territorios por medio de la congregación de una "comunidad minera" (sensu Knapp 1998) y de un sistema organizado en que se coordinan e interrelacionan tecnología, infraestructura, abastecimiento y administración, haciendo posible la explotación a gran escala. Frecuentemente, esta transformación del escenario natural conllevó la aparición de paisajes industriales minero-metalúrgicos (Knapp 1999), los cuales se conforman fundamentalmente de tecnologías mineras, sitios de extracción y procesamiento de minerales, campamentos, vías de circulación, áreas o sitios de almacenamiento y una serie de sectores de apoyo a la producción minera y la circulación de las materias primas (p.ej. producción de alimentos, recolección de frutos, agua o materias primas, etc.). La constitución de un paisaje minero-metalúrgico es más que un problema limitado a la dimensión tecnológica ya que la base económica de una sociedad es fundamental para la forma en que se articula dicho paisaje. Pero también la organización social es una variable que determinará directamente los sistemas de producción (Costin 2001) ya que de las instituciones existentes y de las relaciones sociales entre productores y consumidores dependerá la configuración y funcionamiento de las unidades de producción que participan en las distintas fases de la cadena productiva. En los Andes, en particular, y en las sociedades tradicionales, en general, los paisajes minero-metalúrgicos se articularon 


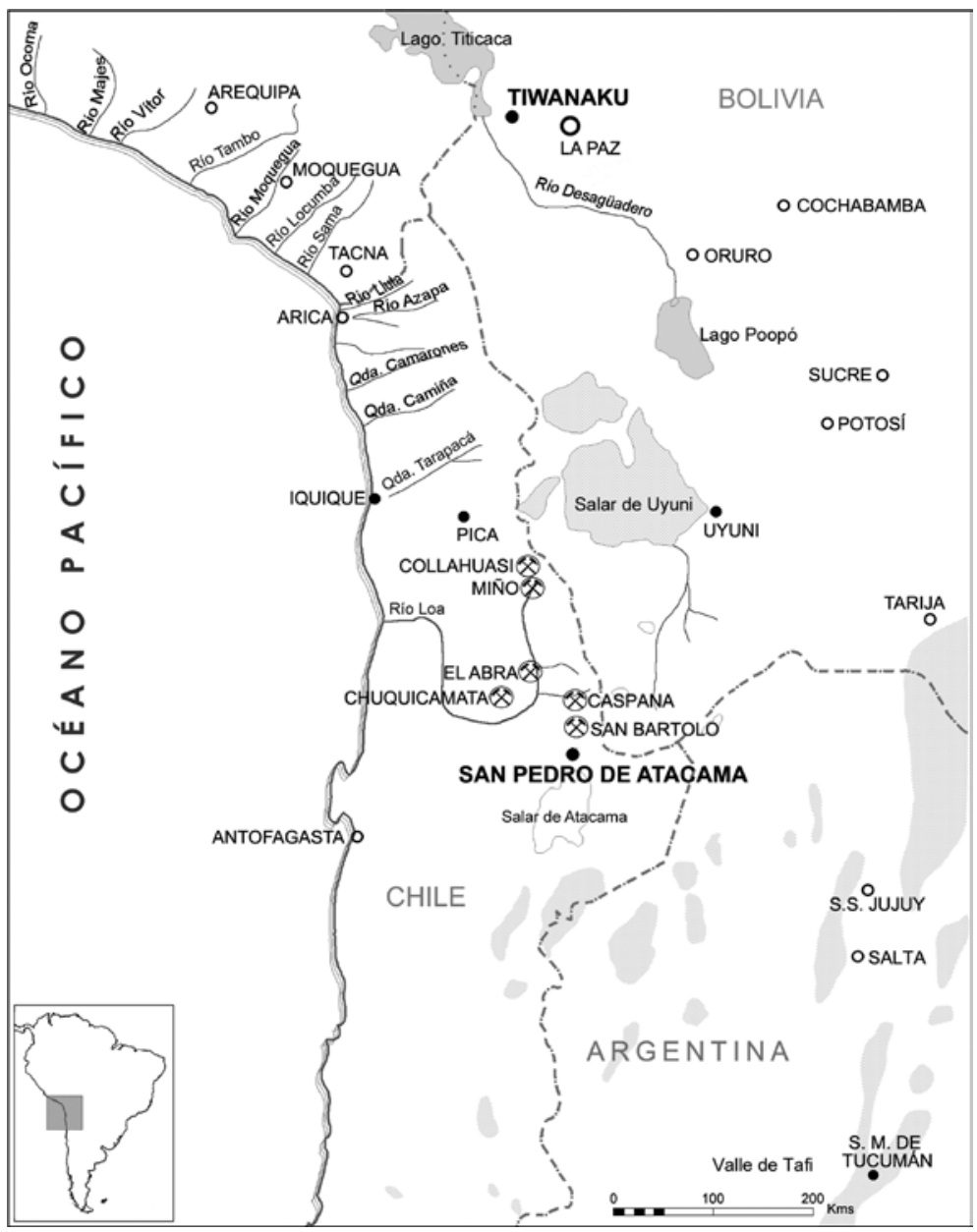

Figura 1. La Región atacameña y el altiplano sur de Tarapacá en el marco de los Andes Meridionales. The Atacama Region and the Southern Altiplano of Tarapacá in the context of the Southern Andes.

también en función de los marcos conceptuales propios de cada cultura, incorporando valores, ideas y creencias acerca de las minas, los minerales y el escenario geográfico regional (Cf. Absi 2003; Bouysse-Cassagne 2004, 2008; Eliade 1974; Salazar-Soler 2002, entre otros). Lo anterior considerando que para las sociedades tradicionales la producción es una actividad que involucra tanto la dimensión material como lo que en Occidente denominaríamos lo sobrenatural, siendo por tanto fundamentales los "rituales de producción" (sensu van Kessel 1989) para el éxito del proceso. Por lo tanto, el estudio de los sistemas minero-metalúrgicos nos permite adentrarnos en la comprensión de un sistema social completo, incluyendo incluso aspectos como la dimensión simbólica. El concepto de paisaje minero-metalúrgico que usamos en este trabajo consiste justamente en la materialización concreta en un tiempo y espacio limitados, de los saberes tecnológicos disponibles, de las principales instituciones económicas, sociales y políticas, y de los conocimientos y concepciones en torno a la minería y metalurgia de una sociedad dada. Consideramos que este concepto permite dinamizar nuestra propuesta anterior respecto de las variables que inciden en la organización de los sistemas de producción mineros (Cf. Salazar 2003-2004; Salinas y Salazar 2008), coincidiendo con el "enfoque holístico" propuesto por Shimada (1994; Shimada et al. 2007) a partir del cual la tecnología minero-metalúrgica es vista dentro de su contexto social, económico, político y simbólico. No obstante su destacado potencial para la comprensión del fenómeno de la producción 
minera prehispánica, este tipo de aproximación ha sido escasamente utilizada para el estudio del caso incaico en el norte de Chile.

\section{Antecedentes sobre Minería Preincaica}

Comprender un paisaje minero-metalúrgico incaico implica también dar cuenta de las transformaciones que instauró respecto de los sistemas de producción previos y sus particulares materializaciones espaciales. En este contexto, podemos señalar que durante el período Intermedio Tardío (ca. 1.000-1.400 d.C.) la minería del cobre en el norte de Chile estuvo destinada a lo menos a cuatro contextos de producción y consumo diferentes, los cuales se advierten con claridad a partir de la arqueología de la región atacameña, pero también están comenzando a ser discernibles en el caso de las tierras altas de Tarapacá: (i) la lapidaria, en especial la fabricación de cuentas de collar (García-Albarido 2007), (ii) el uso del mineral molido como ofrenda, tanto en sitios caravaneros como en los poblados locales (Cf. Aldunate y Castro 1981; Angiorama 2007; Berenguer 2004; Nielsen 2003, entre otros), (iii) el uso del cobre como colorante en el arte rupestre (Sepúlveda y Laval 2010) y (iv) la metalurgia (Aldunate y Castro 1981; Cervellino y Téllez 1980; Figueroa et al. 2010; Hermosilla y Barrera 2010; Núñez et al. 2003; Zori 2011; Zori y Tropper 2010). Recientemente, hemos datado un área de metalurgia extractiva en Incaguasi-Loa correspondiente a este período (cal. 1.260-1.290 d.C.), así como hornos tipo huaira en el área de Miño (cal. 1.290-1.410 d.C.)
(Berenguer 2007; Salazar et al. 2011). Estos últimos son muy semejantes a los reportados en fechas contemporáneas por Zori (2011) para el curso medio y superior de la quebrada de Tarapacá.

El uso de minerales de cobre en sistemas de producción y consumo diversos indudablemente implicó aumentos en la demanda regional de este tipo de recurso. No en vano para el Intermedio Tardío las evidencias directas de minería extractiva son más numerosas que para los períodos anteriores, a lo menos en la cuenca superior del río $\mathrm{Loa}^{2}$. Sabemos, por ejemplo, que durante este período hubo una activa explotación de turquesa y oxidados de cobre en El Abra (Núñez 1999; Núñez et al. 2003; Salazar 2002; Salazar, Salinas et al. 2010), donde se han documentado a lo menos cinco minas del Intermedio Tardío, contándose para cuatro de ellas con dataciones radiocarbónicas, en tanto una ha sido adscrita cronológicamente a partir del material cerámico recuperado en superficie (Tabla 1).

Los yacimientos de Chuquicamata sin duda también estuvieron en explotación en este período, a juzgar por las dataciones directas realizadas sobre martillos mineros encontrados a comienzos de siglo en dicho sector (Bird 1979; Figueroa et al. 2012). Por su parte, las fechas radiocarbónicas reportadas por Aldunate y colaboradores para San Bartolo (Aldunate et al. 2006, 2008) sugieren explotaciones mineras y eventualmente metalurgia extractiva efectuadas durante el Intermedio Tardío en ese sector (1.230 d.C. de acuerdo a un fechado por termoluminiscencia), mientras que en el extremo meridional del área circumpuneña se ha constatado la presencia de un enclave minero atacameño destinado

Tabla 1. Fechados radiocarbónicos de evidencias directas de minería durante el período Intermedio Tardío en El Abra. Las fechas han sido calibradas usando el programa INTCAL 04.

Intermediate Period radiocarbon dates from direct evidences of mining at $\mathrm{El} \mathrm{Abra}$. All dates were calibrated using the INTCAL 04 curve.

\begin{tabular}{|c|c|c|c|c|c|c|}
\hline Sitio & Contexto fechado & Muestra & C-14 a.p. & $\begin{array}{c}\text { cal. a.C./d.C. } \\
\text { (2 sigmas) }\end{array}$ & $\begin{array}{c}\text { Sigla de } \\
\text { laboratorio }\end{array}$ & Referencia \\
\hline Cerro Turquesa & $\begin{array}{c}\text { Estructura habitacional } \\
\text { junto a mina }\end{array}$ & Carbón de fogón & $930+40$ & $1.020-1.200$ d.C. & Beta-217772 & $\begin{array}{l}\text { Salazar, Salinas } \\
\text { et al. } 2010\end{array}$ \\
\hline Cerro Turquesa & Desmonte mina & Pala de madera & $910+50$ & $1.020-1.240$ d.C. & Beta-217771 & $\begin{array}{l}\text { Salazar, Salinas } \\
\text { et al. } 2010\end{array}$ \\
\hline AB-22/39 & Desmonte mina & Pala de madera & $830+40$ & $1.160-1.270$ d.C. & Beta-287255 & En este trabajo \\
\hline AB-22/39 & Desmonte mina & Carbón aislado & $640+80$ & $1.250-1.430$ d.C. & Beta-147523 & Salazar 2008 \\
\hline AB-178 & $\begin{array}{c}\text { Estructura habitacional } \\
\text { junto a mina }\end{array}$ & Carbón de fogón & $650+40$ & $1.280-1.400$ d.C. & Beta 239855 & En este trabajo \\
\hline $\mathrm{AB}-82$ & $\begin{array}{c}\text { Estructura habitacional } \\
\text { junto a mina }\end{array}$ & Carbón de fogón & $600+40$ & $1.290-1.420$ d.C. & Beta 184055 & Salazar 2008 \\
\hline
\end{tabular}


a la explotación de mina Las Turquesas durante el Intermedio Tardío, fechado entre los cal. $1.310 \mathrm{y}$ 1.370 d.C. (González y Westfall 2005; Westfall y González 2010).

En conjunto, las evidencias directas e indirectas revisadas vienen a ratificar la existencia de una consolidada actividad minera en Atacama (y posiblemente en el altiplano sur de Tarapacá) durante el Intermedio Tardío, la cual abasteció a lo menos cuatro ámbitos productivos y funcionales significativos, tanto al interior de la sociedad local como en el ámbito del intercambio con sociedades vecinas. No sólo se contaba con una tecnología minera desarrollada y un profundo conocimiento de los recursos cupríferos locales, sino que, además, se pusieron en funcionamiento estrategias socioeconómicas diversas y complementarias de acceso y explotación de dichos recursos, generando de este modo paisajes minero-metalúrgicos particulares a la realidad biogeográfica, geológica y social de las faenas productivas y de las comunidades que las protagonizaron. Estos paisajes incluyeron el establecimiento de enclaves en zonas distantes y carentes de recursos locales, siendo abastecidas por caravanas de llamas que trasladaban productos desde la costa y los valles, tal como sucedió en Las Turquesas. En estos casos, debieron movilizarse contingentes significativos de población durante temporadas prolongadas. En El Abra, en cambio, así como posiblemente en Chuquicamata, se organizó un paisaje productivo diferente, caracterizado por una ocupación del espacio dispersa, de baja intensidad en términos de alteración de la naturaleza, y sin jerarquía evidente entre los asentamientos. Este paisaje productivo es resultado de un sistema de asentamiento en el cual grupos de tarea de mineros o mineros-caravaneros acceden desde las aldeas y estancias de oasis por cortas temporadas a trabajar en la obtención de los recursos mineralizados (Núñez et al. 2003), posiblemente autoabasteciéndose y generando inversiones de escasa envergadura en las áreas de producción. Las actividades metalúrgicas se realizaron en áreas con combustible local (queñoa, llareta o algarrobo), tanto dentro de las aldeas como en sitios de tarea, y fueron, por lo general, de baja escala y siguiendo un patrón disperso, tal como ha sido sugerido recientemente para la quebrada de Tarapacá (Zori 2011).

Las autoridades incaicas, por lo tanto, no sólo se habrían encontrado con una larga experiencia tecnológica minero-metalúrgica, sino también con una organización socioeconómica altamente eficiente en términos de la producción y distribución de minerales cupríferos. A continuación revisaremos las principales evidencias directas de minería inca en Atacama y el altiplano sur de Tarapacá, y evaluaremos las transformaciones operadas a partir de la intervención del imperio sobre los sistemas productivos preincaicos.

\section{Antecedentes sobre la Minería Inca en Atacama}

La bibliografía sobre el Inca en el altiplano sur de Tarapacá y en Atacama menciona la existencia de diversas evidencias de explotaciones minero-metalúrgicas. Estas incluyen, de norte a sur: Collahuasi, Miño, El Abra, Conchi Viejo, Chuquicamata, Caspana y San Bartolo (Figura 1). En el caso de Caspana, se suelen mencionar las evidencias de los sitios Cerro Verde, Incahuasi-Inca y Vega Salada (Adán 1999; Adán y Uribe 2005; Uribe y Carrasco 1999). Sin embargo, a excepción de Cerro Verde, los datos sobre las restantes minas de Caspana son discutibles, ya que se trata de operaciones extractivas de data histórica ubicadas cerca de los sitios incaicos. Asumir una funcionalidad minera prehispánica en estos sitios es consecuencia de un argumento circular: los incas están interesados en la minería cuprífera, los sitios en cuestión se encuentran cerca de minas de cobre históricas, en consecuencia fueron minas explotadas por los incas, lo que demuestra a su vez que los incas estaban interesados en la producción minera atacameña. Para evitar la circularidad de nuestros argumentos debemos contar con indicadores seguros e independientes de nuestros supuestos. Sugerimos sine qua non para hablar de evidencias arqueológicas de extracción minera prehispánica es la existencia de martillos mineros (o cabezales de martillos) asociados en forma directa a áreas de actividad tales como minas, desmontes, campamentos o canchas de chancado con contextos prehispánicos seguros y bien datados. Este es un criterio que cumplen la totalidad de minas prehistóricas publicadas a nivel mundial. Por ello, puede afirmarse que, a pesar del consenso existente respecto del interés estatal en la minería local, los únicos contextos mineros incaicos bien datados y controlados son los de El Abra y, en mucho menor medida, Cerro Verde en la localidad de Caspana. Emplearemos estas evidencias para comprender mejor las modalidades de organización de la producción minera atacameña bajo el dominio de los incas (Figura 2) y como contraparte evaluaremos 


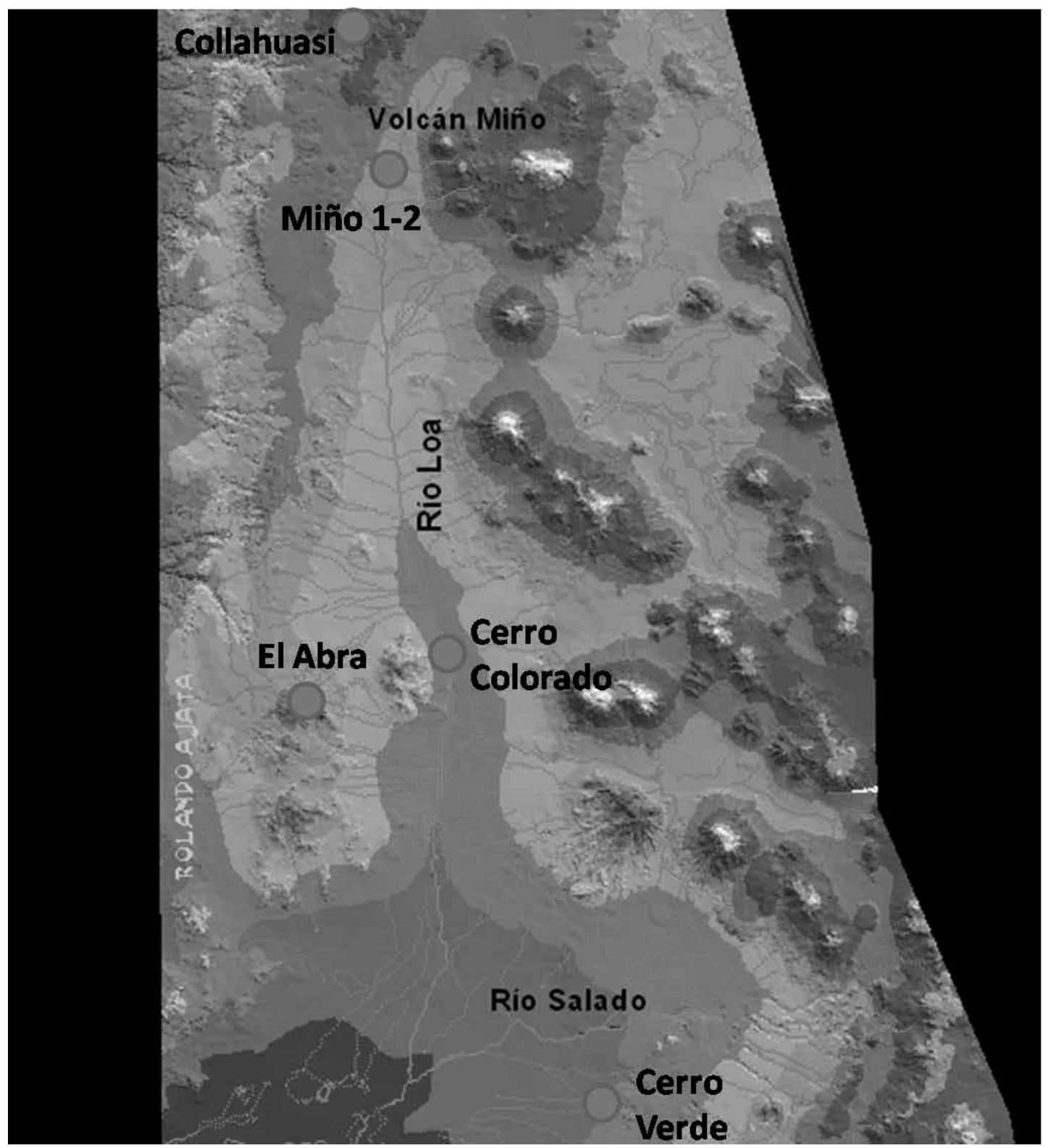

Figura 2. Los sitios mineros y administrativos de Cerro Verde, El Abra-Cerro Colorado y Miño-Collahuasi en la subregión del Loa Superior.

Mining and administrative sites of Cerro Verde, El Abra-Cerro Colorado and Miño-Collahuasi in the Upper Loa subregión.

los datos actualmente disponibles para el distrito Miño-Collahuasi, en el altiplano sur de Tarapacá.

\section{Cerro Verde}

El sitio Cerro Verde (Figura 3) es posiblemente el centro provincial más importante construido por los incas en la cuenca del río Loa. Se ubica en una explanada en la confluencia de los ríos Caspana y Curte, a una altura aproximada de $3.100 \mathrm{msm}$. Presenta cuatro sectores principales de edificación, todos ellos siguiendo un planeamiento y estilo constructivo de carácter incaico (véase Adán 1999; Adán y Uribe 2005). El sector alto del sitio, ubicado sobre una explanada rocosa, presenta un ushnu, el único reportado hasta la fecha para territorio atacameño. Pero este no es el único atributo que hace del sitio un asentamiento excepcional a nivel regional. 


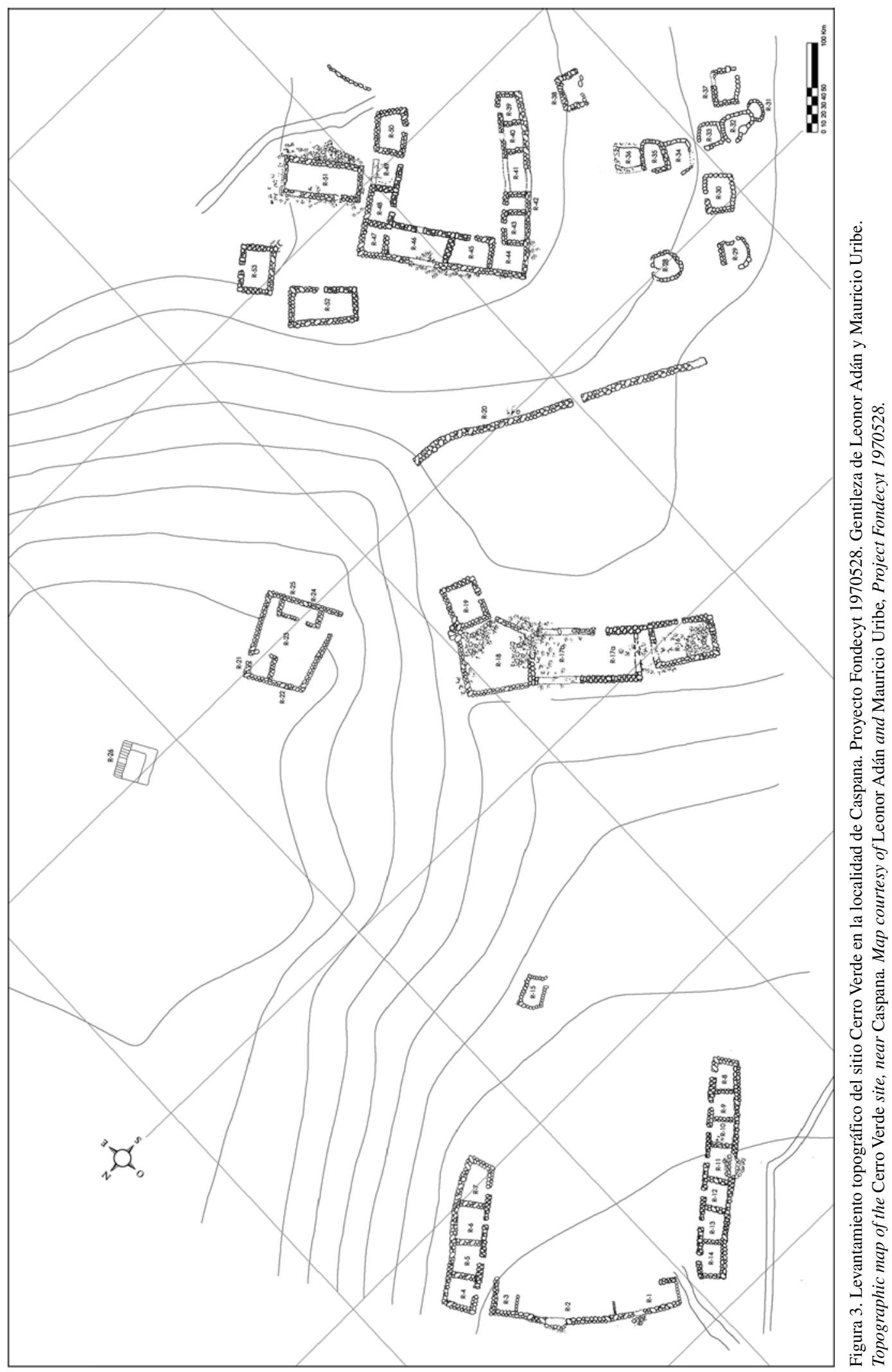


Nos interesa destacar cuatro características centrales: (i) el sitio fue instalado en un lugar sin ocupaciones Intermedio Tardías previas (es decir, es un sitio Inca puro); (ii) en este sitio se expresa con singular claridad la arquitectura incaica, tanto en términos de trazado, tipos de edificio y formatos de construcción, demostrando una diferencia notoria con la arquitectura contemporánea de las poblaciones locales (Adán 1999:24); (iii) el sitio se ubica en un sector privilegiado en términos de geografía sagrada, toda vez que se emplaza entre dos confluencias de quebradas (o pallca, sabido lugar sagrado para los incas) ${ }^{3}$, inmediatamente al norte de una qaqa o afloramiento rocoso singular (Cf. Cruz 2006; Dean 2010) y en el caso del ushnu sobre un promontorio rocoso con una destacada panorámica de los volcanes tutelares locales y de la vega de Turi; (iv) en el sitio destacan espacios públicos a manera de plazas y kanchas, que demuestran que allí se realizaron actividades públicas incluyendo rituales colectivos y el agasajo de las poblaciones locales.

Estas características sitúan a Cerro Verde en el contexto de un conjunto numeroso de centros provinciales construidos especialmente por los Incas de acuerdo con los principios cosmológicos y sociales promovidos por el estado (Acuto 1999; Farrington 1999; Hyslop 1990; Raffino 1981, entre otros) y en los cuales se llevaron a cabo importantes actividades burocráticas, diplomáticas, productivas y/o rituales. La espacialidad y materialidad de estos sitios contribuyeron a la creación de paisajes de desigualdad social, conmemoración ritual y control (sensu Acuto 2012), que a su vez legitimaron y reprodujeron la dominación incaica sobre las poblaciones locales (Acuto 1999).

Lo que nos interesa destacar de Cerro Verde en comparación con otros centros incaicos en las provincias sometidas, es la estrecha y explícita relación del sitio con la minería del cobre. En efecto, unos 300 metros al sur del sitio se encuentran evidencias de minería prehispánica. A pesar de encontrarse afectadas por explotaciones subactuales, destaca la presencia de numerosos cabezales de martillos líticos, desmontes prehispánicos, algunos frentes de explotación prehispánicos y pequeñas estructuras asociadas a dichas explotaciones. Más aún, justo sobre los piques mineros y comunicado con la parte ceremonial de Cerro Verde por medio del camino inca, se encuentra un campamento minero prehispánico, en el cual se advierten bases de

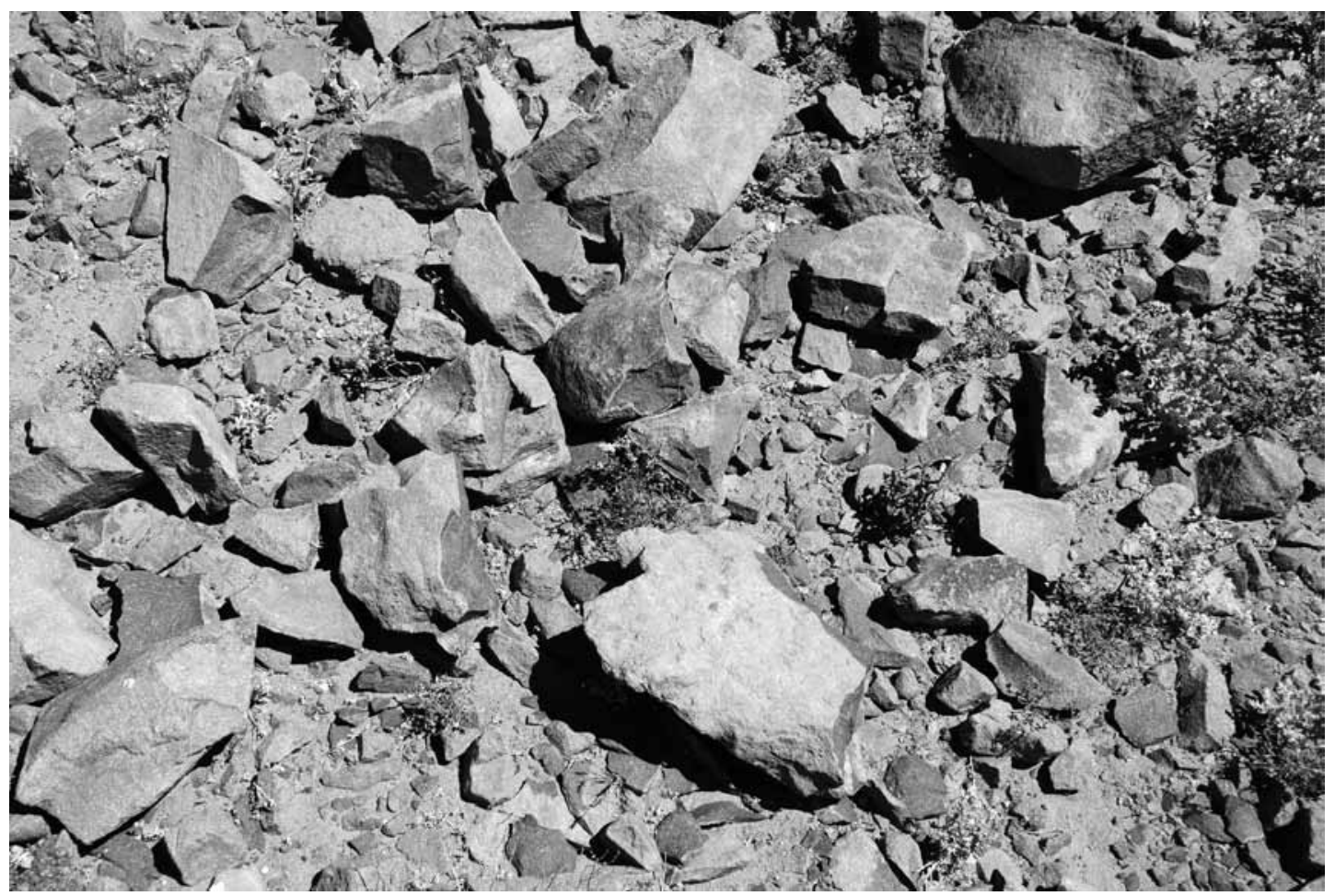

Figura 4. Desechos y percutores líticos en una cantera para la fabricación de martillos junto al campamento minero de Cerro Verde. Lithic debris and hammerstones from an andesite quarry for preparing hammers, near the mining camp of Cerro Verde. 
muro de factura incaica, cerámica Inca-Local y del componente Loa-San Pedro y decenas de cabezales de martillos mineros y restos de mineral molido ${ }^{4}$. Por último, en las laderas de cerro hacia el sur y el oeste del campamento minero recientemente hemos descubierto áreas de preparación de cabezales de martillos líticos a partir de lajas de andesita, conformando verdaderas canteras (Figura 4).

De esta manera, podemos afirmar que el principal centro incaico de "Atacama la Baja" se erigió junto a una explotación minera y notoriamente más alejado de sitios de producción agrícola o pastoril, e incluso de los centros poblados de la región. Volveremos sobre esta idea más adelante. Por ahora conviene evaluar otras evidencias de minería en Atacama.

\section{Los Complejos Mineros de San José del Abra y San Pedro de Conchi}

Las localidades de El Abra y Conchi Viejo (Figura 5) se ubican entre 12 y 25 kilómetros al oeste del curso superior del río Loa, con alturas de entre 3.500 y $4.000 \mathrm{msm}$. Dos complejos mineros extractivos incaicos han sido identificados a la fecha en estas localidades. Estos han sido publicados en trabajos previos (p.e. Núñez 1999; Salazar 2002, 2002-2005, 2008, entre otros), por lo que no nos detendremos en los detalles de los sitios. Baste señalar que el Complejo Minero San José del Abra está compuesto por seis sitios arqueológicos que incluyen un campamento habitacional con 40 estructuras pircadas (Inkawasi-Abra), una mina indígena prehispánica compuesta por varios piques y operaciones menores (AB-22/39), áreas de chancado (AB-37 y AB-38), bodegas (AB-48), senderos dentro del complejo y para conectar con sitios en quebradas vecinas, áreas de carga y descarga de animales (AB-38) y plataformas rituales (AB-39 y AB-40). Un conjunto de sitios emplazados en las quebradas adyacentes cumplieron funciones de apoyo logístico a las labores productivas desarrolladas en los sitios principales del complejo (p.ej. Ichunito,

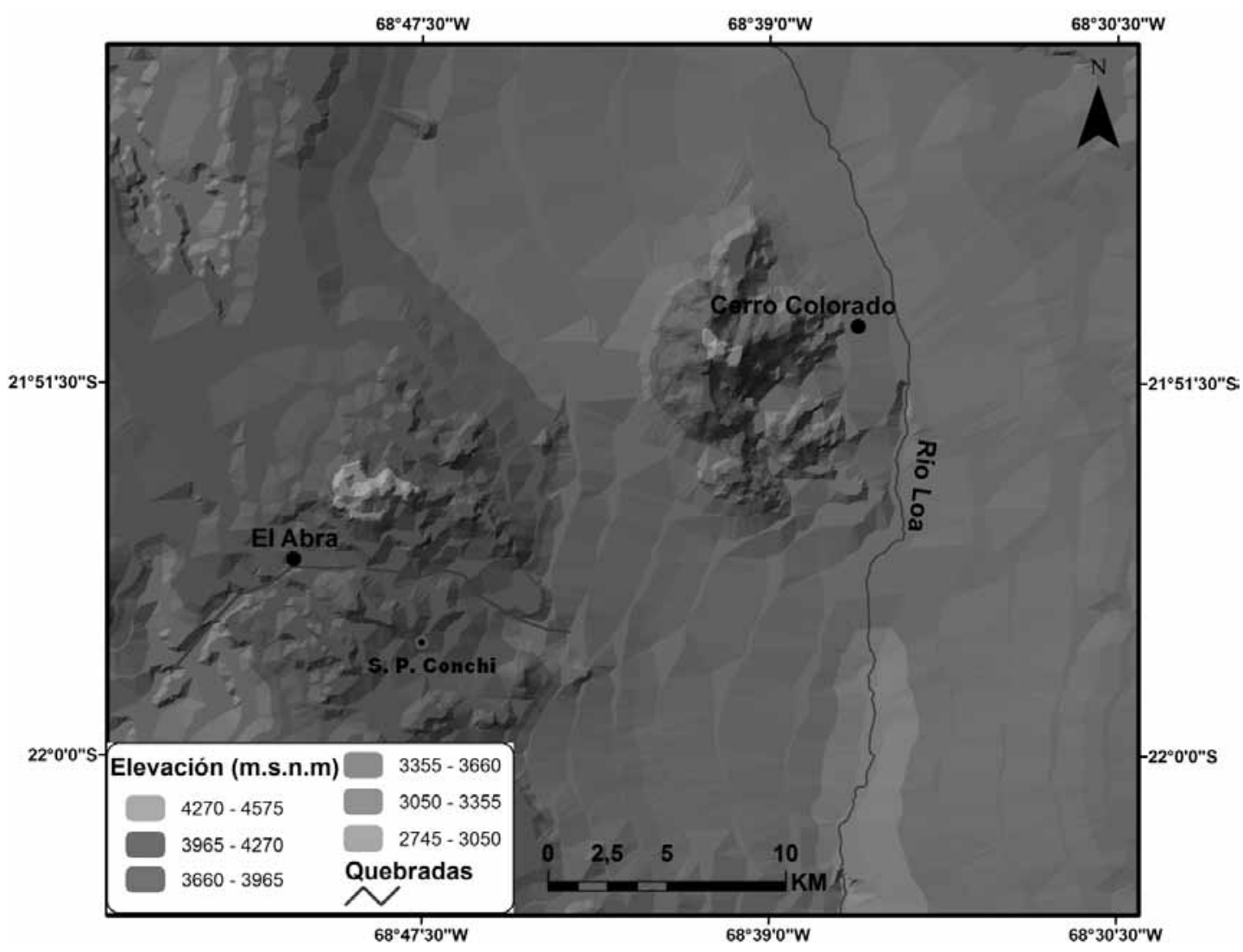

Figura 5. Los Complejos Mineros de San José del Abra y San Pedro de Conchi, en las localidades homónimas.

The San José del Abra and San Pedro de Conchi mining complexes. 
AB-44, AB-73) (Salazar 2008). Todos estos sitios fueron ocupados en forma predominante durante el Período Tardío (1.400-1.540 d.C.), pero también evidenciaron un uso durante el Período Intermedio Tardío, al menos en el caso de la mina indígena (AB-22/39) y los sitios inmediatamente asociados (AB-37 y AB-38). Es decir, se trata de un fenómeno de reexplotación de yacimientos en operación antes de la expansión del Tawantinsuyu en Atacama (Salazar 2002-2005), tal como lo demuestran las fechas para uno de los sectores del sitio AB-22/39 (Tabla 1).

Los estudios más recientes demuestran que la administración incaica conllevó una profunda reorganización de la producción minera en El Abra, aun cuando haciendo uso de fuerza de trabajo local y utilizando los conocimientos, infraestructura y tecnología propias de las poblaciones atacameñas. No solamente son notorios los aumentos en los volúmenes de producción entre el Intermedio Tardío y el Tardío, sino que además los mineros fueron concentrados en un campamento habitacional y destinados a la explotación de un solo yacimiento (AB-22/39). Esto marca un contraste con el patrón de diversas operaciones de baja escala que caracterizó la actividad minera local durante el Intermedio Tardío (Salazar 2002-2005). Vale decir, se dio un cambio desde un patrón disperso de producción a uno nucleado (Cf. Costin 2001; Zori 2011), medida que evidentemente permite maximizar la producción y disminuir los costos de control y administración de la misma. Más aún, el hallazgo de fragmentos de Spondylus en una plataforma ceremonial ubicada en un lugar central de la mina AB-22/39 sugiere que el Estado Inca también controló la ritualidad asociada a la explotación de minerales de cobre por medio de la circulación de bienes exóticos a la localidad y de alto contenido simbólico en los Andes y en el Tawantinsuyu en particular. En el campamento habitacional, por su parte, la materialidad predominante es de carácter local. Sin embargo, la administración estatal reservó un sector particular dentro del sitio (separado de las restantes estructuras por el cauce de la quebrada Casicsa), para instalar arquitectura de rasgos incaicos (Figura 6). Este espacio se asocia a actividades de preparación de alimento a gran escala, muy posiblemente como parte de las estrategias de comensalismo político incaicas, y corresponde, además, al área con mayores índices de frecuencia de cerámica Inca Provincial a nivel de todo el sitio (Salazar et al. 2012).
El segundo complejo minero identificado en la localidad corresponde al de San Pedro de Conchi, ubicado al noroeste del poblado actual de Conchi Viejo y a unos 10 kilómetros al sur del complejo anterior. Este Complejo Minero consta de los mismos elementos que en el caso de El Abra: operaciones mineras prehispánicas (dos trincheras y operaciones extractivas menores), áreas de chancado, un corral, un campamento minero, un edificio de patrón arquitectónico Inca-Local, aparentemente vinculado con actividades ceremoniales y algunas estructuras de función aún indeterminada. Al igual que en el caso de El Abra, acá durante la ocupación incaica la población de mineros dispersos se concentró en el campamento AB-184 y la explotación minera se focalizó en el sitio AB-99.

En síntesis, durante el Período Tardío se reconfigura profundamente en El Abra la actividad productiva de oxidados de cobre y turquesa. El Tawantinsuyu controla dicho proceso por medio de la reorganización de la fuerza de trabajo, su financiamiento en términos de alimentación e instrumentos de trabajo, y el control de la tecnología simbólica y los rituales de producción (sensu van Kessel 1989) necesarios para el funcionamiento de los sistemas productivos andinos.

Como ya se señaló, los dos complejos mineros reorganizados por los incas se ubican a unos 20 kilómetros de distancia del río Loa, donde se encuentra un ramal del Qhapaq Ñan y alrededor de 10 sitios construidos durante el Período Tardío que jalonan y articulan a intervalos más o menos regulares el tránsito a lo largo de 125 kilómetros de la arteria imperial del Alto Loa (Berenguer 2007; Berenguer et al. 2005). En trabajos anteriores, hemos llamado la atención acerca de la relación entre el sector de El Abra y el Alto Loa y, en particular, entre los dos complejos mineros y el sitio Cerro Colorado (SBa162), un segundo centro provincial construido por los Incas en Atacama La Baja y que habría operado como lugar de agasajo a las poblaciones de mitayos que trabajaban en las minas de El Abra y Conchi (Berenguer 2007).

El sitio se ubica en la Pampa Cuestecilla, en el curso superior del río Loa, a unos $3.200 \mathrm{msm}$ (Berenguer 2004). En el sector norte se han registrado tres conjuntos arquitectónicos de trazado ortogonal, en la cual predominan atributos constructivos y de planeamiento incaicos (Berenguer 2007; Castro 1992; Cornejo 1995; Uribe y Urbina 2009; Urbina 


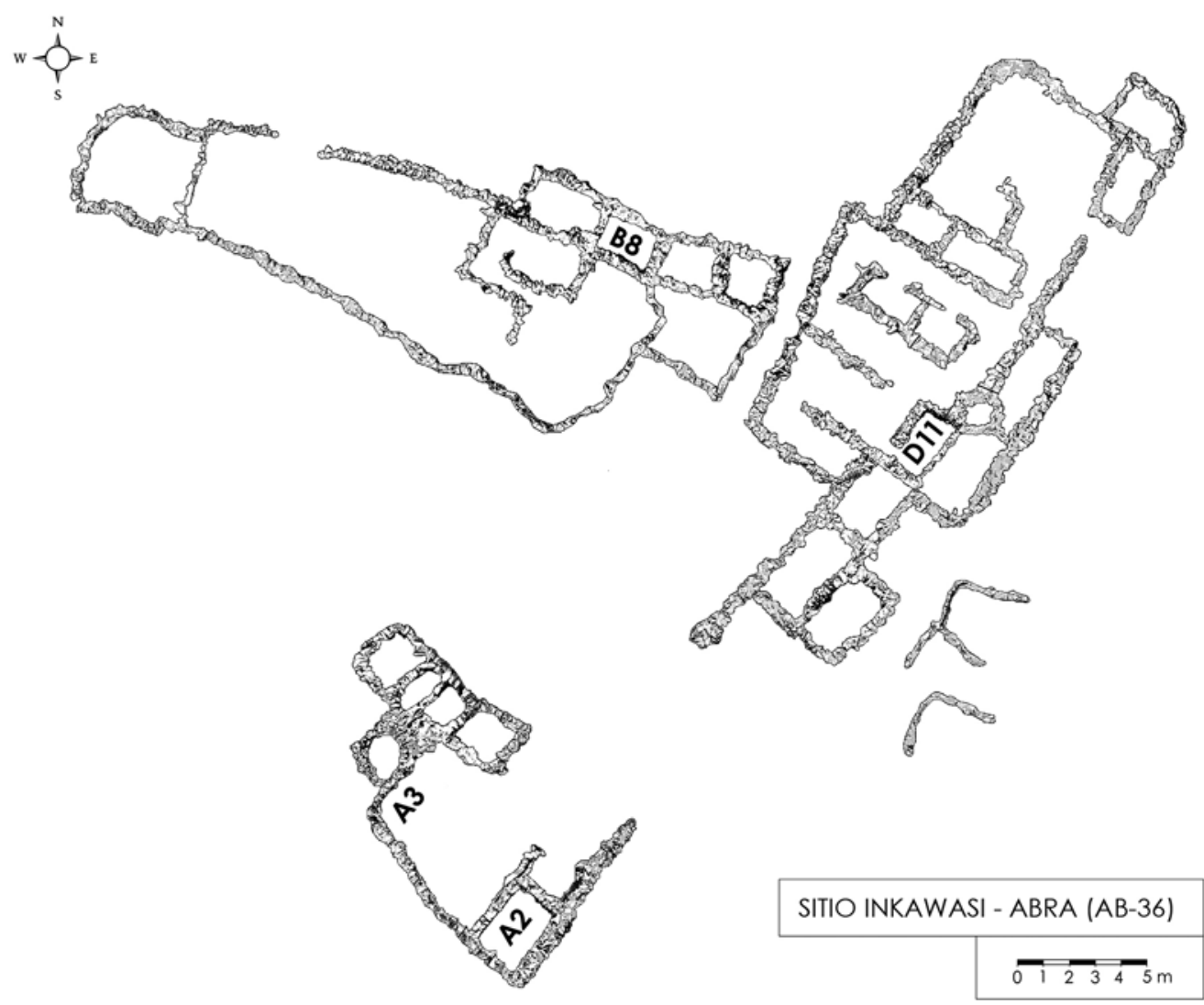

Figura 6. Levantamiento topográfico del sitio Inkawasi-Abra y ubicación de la arquitectura incaica. Modificado de Núñez (1999). Topographic map of the Inkawasi-Abra site showing the location of inka architecture.

y González 2004, entre otros). Destaca la presencia de una plaza de 70 x 50 metros que concentró la actividad pública y ritual en este sitio. La plaza está alineada con un rasgo orográfico excepcional, cual es el Sirawi ${ }^{5}$, el cual posiblemente haya constituido una qaqa (sensu Cruz 2006; véase también Dean 2010). La cerámica recuperada evidencia uno de los porcentajes más altos de Cusco-Polícromo de la región atacameña, a lo que se asocia la presencia aunque minoritaria de cerámica Yavi, Saxamar y tipos inca-locales TPA y TRN, además del predominio de la cerámica local atacameña de los Períodos Intermedio Tardío y Tardío (Uribe y Urbina 2009).

En síntesis, formal y funcionalmente Cerro Colorado parece muy semejante a Cerro Verde, aun a pesar de las probables jerarquías disímiles de ambos sitios. Por su parte, los complejos mineros en El Abra son equivalentes al campamento y áreas de trabajo ubicadas a 300 metros al sur del sitio Cerro Verde. Estos datos sugieren, al menos para "Atacama La Baja", una estrecha relación entre los centros mineros controlados por los incas y los centros provinciales construidos por el estado.

\section{El Distrito Miño-Collahuasi}

Actualmente, nuestro equipo se encuentra investigando la articulación entre instalaciones incaicas y evidencias de actividades minero-metalúrgicas en el Distrito Miño-Collahuasi, con el objeto de profundizar nuestra comprensión de la diversidad de paisajes minero-metalúrgicos instaurados por los incas en el Norte Grande de Chile. Este distrito se halla unos $50 \mathrm{~km}$ al norte del sitio Cerro Colorado, entre la cuenca de Ujina, Región de Tarapacá, y las cabeceras del río Loa en Miño. Las condiciones 
geoclimáticas imposibilitan aquí todo tipo de agricultura, incluyendo cultivos resistentes al frío, como la quínoa. No obstante, existe en el sector una importante ocupación incaica, dentro de la cual destacan los sitios Miño-1 (31 recintos, $3.810 \mathrm{msm}$ ) y Miño-2 (33 recintos, $3.932 \mathrm{msm}$ ) ubicados en la localidad homónima, y Yabricoyita o CO-37 (161 recintos, $4.250 \mathrm{msm}$ ), situado 25 kilómetros al norte de los anteriores, en la localidad de Collahuasi, cuenca de Ujina, en el altiplano sur de Tarapacá.

Miño-1 y Miño-2 destacan por poseer el único conjunto de kallankas, plazas y kanchas o RPC en $180 \mathrm{~km}$ a la redonda, lo que lo convierten en el tercer y último centro provincial construido expresamente por los Incas en la cuenca del río Loa (Figura 7). En efecto, comparten el mismo tipo de características antes señaladas para los sitios de Cerro Verde y Cerro Colorado: arquitectura incaica tanto en términos de planeamiento, patrones constructivos y tipos de edificio; ausencia de ocupaciones del Intermedio Tardío; asociación directa con la red vial incaica; altos porcentajes de cerámica Inka Cuzco e Inka Provincial, incluyendo Yavi y Saxamar; vinculación con la geografía sagrada, esta vez con las nacientes del río Loa, frente a un afloramiento rocoso de color rojo (qaqa) en el caso de Miño 1 y a los pies del volcán Miño (Castro 1992; Berenguer et al. 2005; Berenguer 2007; Uribe y Cabello 2005; Uribe y Urbina 2009).

A $25 \mathrm{~km}$ hacia el norte de Miño, el sitio Yabricoyita presenta RPC, corrales, cuartos, plazas y collqas (Lynch y Núñez 1994; Romero y Briones 1999), así como gran cantidad de cerámica Inka Provincial y Cuzco Policromo (Berenguer et al. 2011a). El sitio se ubica algo alejado del camino inca y presenta ocupaciones tanto del Intermedio Tardío como del Tardío (Figura 8). El emplazamiento del sitio, así como la presencia de minerales de cobre y escorias en superficie, ha llevado a los investigadores a considerarlo un sitio de función minero-metalúrgica más que un tampu o un centro administrativo (Berenguer et al. 2011a; Lynch y Núñez 1994; Romero y Briones 1999). Cerca de 500 metros al sur del sitio se encuentra el sitio Ujina 8, un área de producción metalúrgica con diversos hornos de piedra y escoriales.

Las características antes enunciadas nos han permitido sostener que Miño 1 y Miño 2 forman parte de un mismo complejo administrativo-ceremonial incaico, el cual parece ser equivalente a los sitios de Cerro Colorado y Cerro Verde en el Loa Superior.
Dada la ubicación de estos últimos sitios y su participación dentro de los paisajes minero-metalúrgicos incaicos del Loa Superior, trabajamos actualmente con la hipótesis de que los sitios de Miño también ejercieron un rol funcional análogo (Cf. Berenguer 2007, 2010; Berenguer et al. 2011a).

La presencia de un fragmento de lingote de metal detectado en estratigrafía al interior de la única kallanka (E13) de Miño-2, sugiere que efectivamente existe una vinculación de estos sitios con la administración de la actividad minero-metalúrgica y el control de los productos intermedios de la cadena productiva, aun cuando se trata de solo un ejemplar (Figura 9). Dos fechas se conocen para esta estructura -cal. 1.440-1.629 d.C. (Beta-291619) y cal. 1.410-1.500 d.C. (Beta-203029)-, las cuales en conjunto con la arquitectura y la cerámica dominante confirman la asociación del lingote al período incaico (Berenguer et al. 2011b). Por su parte, análisis de fluorescencia de rayos X y PIXE realizados recientemente en este lingote demuestran que se trata de un cobre de alta pureza sin alear (Salazar et al. 2011), sin evidencia de estaño u otros metales alóctonos a la región, pero con presencia de plata como elemento menor, la cual es característica de las menas cupríferas locales, lo que a su vez sugeriría que se trata de un lingote producido a partir de menas del distrito Miño-Collahuasi.

No obstante, aún no está claro dónde exactamente se explotaron los minerales cupríferos del distrito ni dónde se procesaron para convertirlos en lingotes. El proyecto en curso nos ha permitido identificar evidencias de actividades minero-metalúrgicas indígenas en las inmediaciones de los sitios de Miño 1 y 2 , las que incluyen el acopio de minerales de cobre y machacado final previo a su fundición (Miño 19), reducción de minerales de cobre en hornos tipo huaira (Miño 19, Miño 20 y Miño 21), molienda de escorias (Miño 19) y acumulación de goterones y prills de metal en estructuras habitacionales (Miño 22). Sin embargo, el estado de avance actual de nuestra investigación y los datos cronológicos disponibles no permiten todavía vincular estos hallazgos con la ocupación incaica. Por un lado, un carbón de superficie de la fundición del sitio MI-20 arrojó una edad de cal. 1.290-1.410 d.C. (Beta-290989), la cual resulta algo temprana para el Horizonte Inca, mientras que dos fechados de MI-19 sitúan a este sitio en el Formativo Tardío (Beta-324130: cal. 540-650 d.C.; Beta-324131: cal. 420-570 d.C.). Por otro lado, los eventos de 


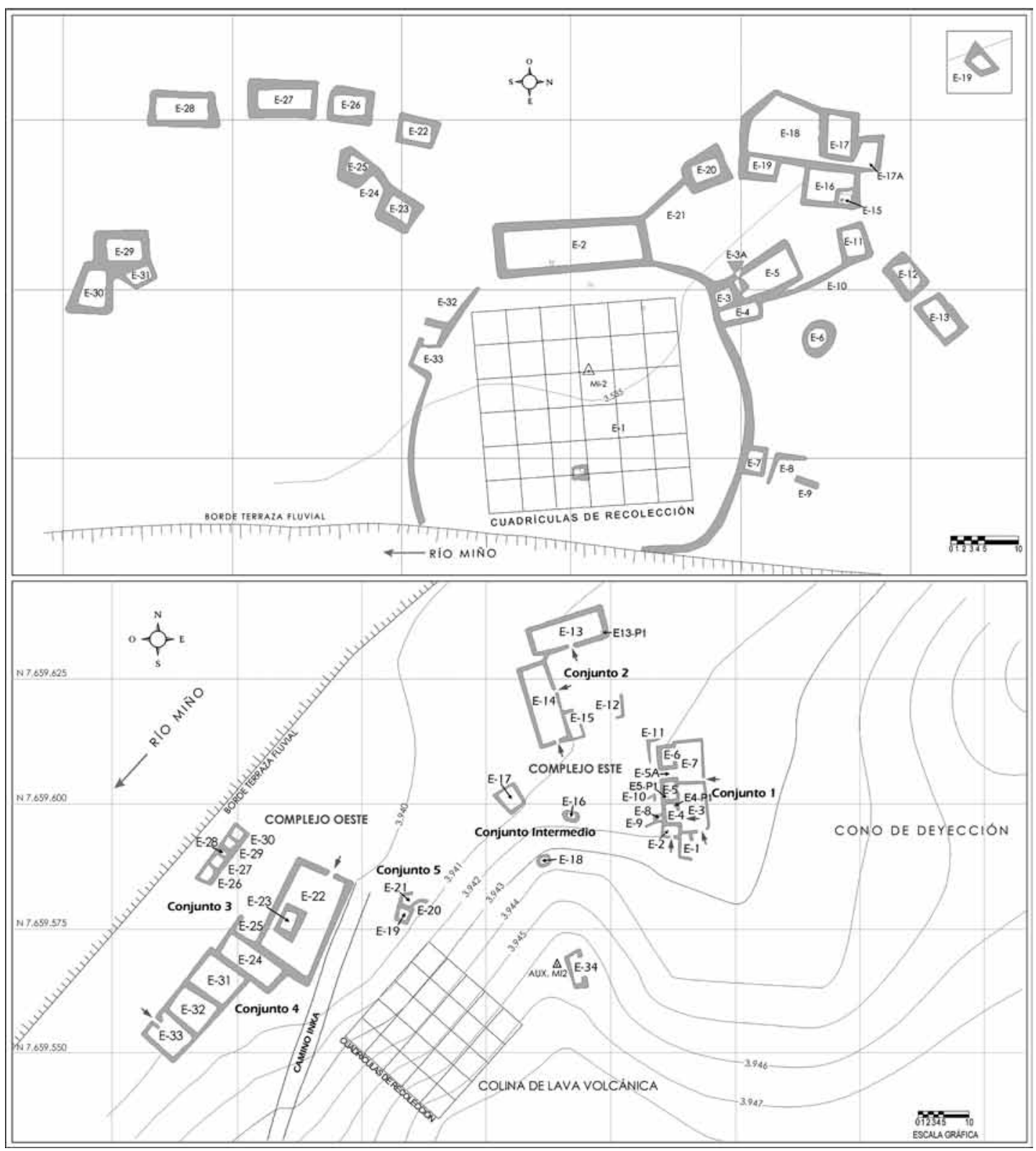

Figura 7. Levantamiento topográfico de los sitios Miño-1 (arriba) y Miño-2 (abajo), en las nacientes del río Loa. Proyecto Fondecyt 1010327.

Topographic map of Miño-1 (upper) and Miño-2 (lower) in the headwaters of the Loa River. Map courtesy of Project Fondecyt 1010327.

fundición de MI-21 y los restos de metal acopiados en MI-22 corresponden a la época colonial a juzgar por las fechas radiocarbónicas (Beta-300552: cal. 1.650-1.950 d.C.; Beta-324132: cal. 1.6601.950 d.C.; Beta-324133: cal. 1.530-1.950 d.C.) y la cerámica en estratigrafía. Además, la pequeña escala de producción evidenciada por estos sitios no parece compatible con una operación controlada u organizada por el Estado Inca. Como contraparte, las evidencias metalúrgicas del sitio Ujina 8, ubicado a 500 metros al sur de Yabricoyita, revelan una intensidad de producción notablemente mayor, pero desgraciadamente el sitio aún no ha sido fechado. No obstante, la presencia de escorias en la superficie 

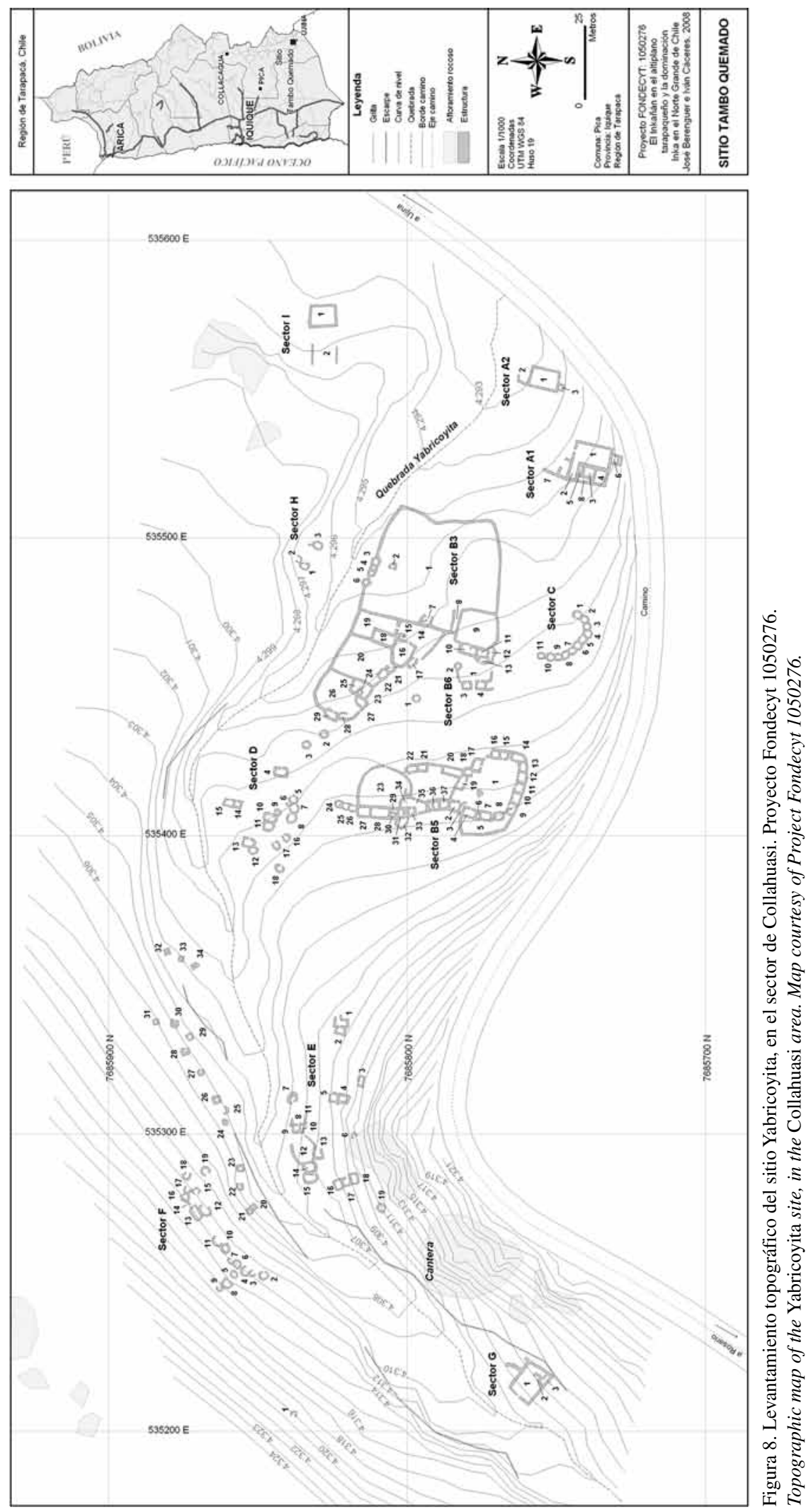


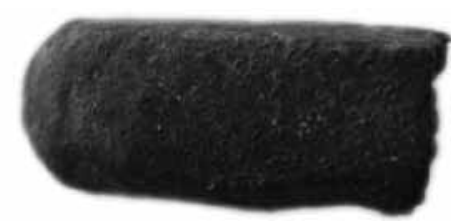

0

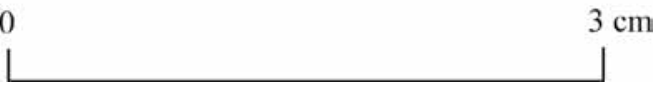

Figura 9. Fragmento de lingote encontrado en la Kallanka de Miño 2.

Ingot fragment found in the Miño-2 Kallanka.

del sitio mismo de Yabricoyita sugiere fuertemente que Ujina 8 funcionó en contemporaneidad con este último, lo que sugeriría una historia productiva desde el Intermedio Tardío hasta el Horizonte Inca.

$\mathrm{Si}$ estos datos se confirman por medio de fechados absolutos y los análisis arqueometalúrgicos del sitio de fundición de Ujina 8, entonces podría plantearse que los sitios de Miño 1 y 2 efectivamente actuaron como centros provinciales que concentraron las actividades ceremoniales y eventualmente administrativas relacionadas con las operaciones minero-metalúrgicas realizadas en el sector de Collahuasi (Yabricoyita y Ujina 8), replicando de esta manera el modelo organizacional descrito para El Abra-Cerro Colorado.

\section{Discusión: Paisajes Mineros en Atacama y el Altiplano sur de Tarapacá bajo el Dominio Inca}

Aun cuando hay información que aún falta para una acabada reconstrucción del paisaje minerometalúrgico incaico en el río Loa y las tierras altas de Tarapacá, estamos en condiciones de ofrecer algunas interpretaciones preliminares. Para ello, es interesante concentrarse en los datos más confiables de que disponemos. Comenzaremos destacando nuevamente las semejanzas entre los tres únicos centros provinciales construidos por los incas en la cuenca del río Loa (Cerro Colorado, Cerro Verde y Miño) ${ }^{6}$ : (i) ninguno de los sitios contaba con ocupaciones del PIT relevantes, es decir, son sitios construidos durante el Período Tardío (sitios Incas puros); (ii) si bien lo mismo puede decirse de tampus más pequeños y aún de chaskiwasis, en los tres sitios comentados se expresan los más altos estándares arquitectónicos incaicos a nivel regional, tanto en términos de organización del espacio, tipos de edificaciones y patrones constructivos, creando de esta manera pequeños espacios incaizados dentro del territorio atacameño (Acuto 1999; Berenguer 2007); (iii) para el emplazamiento de estos sitios se escogieron puntos sobresalientes desde la perspectiva de la geografía sagrada inca (dos pallca en Cerro Verde y qaqas en Cerro Verde, Cerro Colorado y Miño 1). Por su parte, los juegos visuales desde los sitios posiblemente potenciaron la creación de nuevas relaciones y jerarquías entre wakas, incluyendo la posición de los cerros tutelares de la población local en relación con la presencia incaica; (iv) en los tres sitios destaca la presencia de plazas y grandes espacios públicos, lo que sugiere que la funcionalidad predominante parece haber sido ceremonial, lo que es coherente con los livianos depósitos encontrados en la excavación de estos sitios (Adán 1999; Berenguer et al. 2005, 2011b); (v) en estos sitios se despliegan también los más altos porcentajes de cerámica incaica importada (cuzqueña, altiplánica y/o trasandina) del Loa Superior (Uribe y Urbina 20097 ; (vi) todos los sitios se ubican a la vera del Camino Inka.

Los datos disponibles sugieren que existieron diferencias de jerarquía entre estos centros provinciales. Si bien en los tres sitios la relación de la arquitectura pública con la qaqa es una de distanciamiento (sensu Dean 2010), en Cerro Colorado y en Miño 1 los espacios públicos están alineados con la qaqa y, en un segundo plano de visibilidad, y también en una relación de distanciamiento, éstas se alinean con importantes cerros locales -posiblemente wakastales como el volcán Miño y el Cerro Colorado. En Cerro Verde los espacios públicos no están alineados con la qaqa. De hecho, hay escaso contacto visual con ella. No obstante, el ushnu tiene una relación de visibilidad directa tanto con la qaqa como con todos los cerros tutelares de las poblaciones locales de la cuenca del río Salado (Paniri, León y CablorChiza, cf. Castro y Aldunate 2003). Por otra parte, como ya señalamos, el ushnu de Cerro Verde es el único conocido para la región atacameña, lo que enfatiza la predominancia simbólica de este sitio. Esto parece coherente con la mayor cantidad de espacios públicos en este sitio (tres plazas) y con el hecho de que además de la qaqa, Cerro Verde se ubica justo al centro de dos pallcas.

Por motivos de espacio no profundizaremos en interpretaciones acerca de las sugerentes diferencias de jerarquía entre estos centros provinciales. Nos interesa, en cambio, destacar que la ubicación de estos sitios también parece haber 
tenido en consideración la cercanía con centros de explotación minera. En el caso de Cerro Verde esta relación es evidente e incuestionable (Castro 1992; Adán 1999) y quizás el hecho de que el ushnu tenga una relación de visibilidad directa con las áreas de extracción minera fue justamente una de las características que le otorgó al sitio una posición de jerarquía respecto de los restantes centros provinciales. En el caso de Miño y Cerro Colorado la relación de los centros provinciales con la explotación minero-metalúrgica también ha sido planteada con anterioridad (Berenguer 2007), pero esta relación es menos evidente, por cuanto los sitios de producción se encuentran distantes cerca de 20 kilómetros. Pese a ello, es interesante reconocer que ambos centros provinciales se encuentran ubicados intencionalmente frente a qaqas. De acuerdo con información etnográfica, las qaqas se asocian simbólicamente al inframundo y a las divinidades que lo controlan, incluyendo al Tío que habita en el interior de las minas (Cruz 2006). El hecho de que los espacios públicos de Cerro Colorado y Miño se orienten directamente a las qaqas sugiere por lo tanto que las principales celebraciones en estos sitios se vinculaban con la propiciación de los espíritus del inframundo (ukhu pacha). Por lo que es muy posible que estas celebraciones formasen parte de los rituales de producción requeridos para el adecuado funcionamiento de los sistemas de producción mineros instaurados por los Incas.

Es interesante destacar que siguiendo hacia el sur y fuera del territorio atacameño, también se dio una relación espacial explícita entre centros provinciales y producción minero-metalúrgica. Es el caso del sitio Viña del Cerro en Copiapó, que además de los hornos de fundición contiene el único ushnu ubicado en dicha provincia (Niemeyer 1986), así como del sitio Los Infieles en el Valle del Elqui, donde la arquitectura incaica más clara y compleja de la región se asocia directamente a minas de cobre y wakas mineras locales (Cantarutti 2012).

Como la relación de los centros provinciales incaicos no se asoció en todos las regiones del imperio con la minería y las wakas mineras, el patrón que estamos proponiendo para Atacama la Baja y el Altiplano Sur de Tarapacá (posiblemente también Copiapó y el área Diaguita nuclear), ratifican desde una perspectiva complementaria la reconocida importancia de la minería del cobre en la estrategia y estímulo de la expansión imperial hacia el norte de Chile. Y demuestra, además, que para organizar y controlar la producción cuprífera los Incas construyeron un paisaje minero-metalúrgico que integró los sitios de extracción y procesamiento con centros provinciales en los cuales se propiciaban las wakas que controlaban la "fertilidad minera" y posiblemente se agasajaba a las poblaciones que participaban en los distintos ámbitos vinculados a la producción en las minas, incluyendo el abastecimiento y el transporte.

Junto con la importancia de la minería en la economía organizada por los Incas en Atacama y al altiplano sur de Tarapacá, las wakas mineras fueron un elemento fundamental en la reconfiguración de los paisajes sagrados impuestos por el estado a nivel regional (Cruz 2009; Bouysse-Cassagne 2008; Platt y Quisbert 2008) y en la ubicación de los centros provinciales.

En los casos de El Abra y Collahuasi, la distancia entre los sitios productivos y los centros provinciales requirió la conformación de un paisaje minero-metalúrgico más complejo y más visible arqueológicamente que en Cerro Verde, especialmente por la infraestructura requerida en las inmediaciones de las áreas de trabajo, así como en caminos, senderos y sitios de enlace que unieran los complejos minero-metalúrgicos con el centro provincial correspondiente. En los enclaves y sectores productivos alejados de los centros provinciales los Incas también organizaron el espacio, implementaron prácticas de comensalismo político e introdujeron y controlaron rituales de producción a escala local. En efecto, el caso de El Abra revela que en los centros mineros también se habilitaron espacios segregados, exclusivos para el culto y las ofrendas a wakas mineras, posiblemente materializadas en los cerros mismos que eran explotados. Futuros estudios podrían demostrar relaciones de intervisibilidad u orientación entre las distintas wakas mineras e incluso evaluar las relaciones jerárquicas entre ellas tal como se ha propuesto desde la etnografía (Cf. Castro y Aldunate 2003). Por ahora nos conformamos con afirmar que en estos sitios también se evidenció la presencia de un área de preparación comunal de alimentos, asociada a arquitectura y cerámica Inca-Local e Inka Imperial, y segregada del resto del campamento minero por el lecho de la quebrada Casicsa (Salazar et al. 2012). Un pequeño espacio público en el campamento indica que allí se debieron realizar celebraciones y festines para los mineros que trabajaban para el 
Inca. Aún no sabemos si estos mismos ingredientes del paisaje minero-metalúrgico incaico se advierten en el sector de Collahuasi y en particular en el sitio Yabricoyita (CO-37), que pudo actuar como tampu (Lynch y Núñez 1994) y como campamento minero a la vez, o solamente como esto último.

\section{Reflexiones Finales}

Una consideración de la información disponible sobre minería inca en Atacama y el altiplano sur de Tarapacá permite proponer una estrecha articulación entre los sitios de producción, wakas mineras a escala local y regional y los centros provinciales, conformando de esta manera un complejo paisaje minero-metalúrgico como resultado de la consideración simultánea de variables productivas, sociales y simbólicas. Estos paisajes pueden ser clasificados en a lo menos dos modelos de organización socioespacial. En el primero de ellos -caso de Cerro Verde- el centro provincial se ubica adyacente al centro minero y su waka correspondiente (qaqa). En el caso de El Abra y Collahuasi, en cambio, los sitios de producción se encuentran a más de 20 kilómetros de los centros provinciales, los cuales se instalaron junto a waka mineras (qaqas) que comunicaban con las divinidades que controlaban la gestación de los minerales. A lo menos a juzgar por los datos de El Abra, los sectores productivos también contarían con instalaciones más pequeñas (plataformas) donde se habrían desarrollado rituales mineros de menor escala, pero de indudable control estatal, orientados posiblemente a las wakas mineras locales. También se habrían construido aquí sectores incaicos especialmente separados de la población local para albergar las prácticas de comensalismo político estatales.

El hecho de que los centros provinciales se instalen junto a wakas mineras y/o áreas de explotación cuprífera, indica que estos sitios formaron parte de los rituales de producción y del paisaje minero-metalúrgico incaico, pero al mismo tiempo que la celebración de otras festividades estatales que pudieron llevarse a cabo en estos sitios habría congregado a las poblaciones locales en torno a la actividad minera, manteniéndola como un referente simbólico permanente de las actividades públicas propiciadas por el Tawantinsuyu. Lo anterior parece ser parte de las estrategias de conquista ritual incaica (Nielsen y Walker 1999), en cuanto, al elevar las wakas mineras a la categoría de principales a nivel regional, se las vincula directamente con la divinidad del Inca y, por lo tanto, con la propiedad tanto de éste como del culto solar imperial sobre los recursos mineros de los territorios locales. En este sentido, nos parece evidente que los minerales de Collahuasi, El Abra y Cerro Verde fueron minas del Inca y/o del culto solar, lo cual a su vez es coherente con la materialidad, simbolismo y control incaicos ejercidos en las propias faenas productivas. Las diferencias en las modalidades de organización espacial no serían resultado de diferencias en las relaciones de propiedad sobre los recursos mineros, aun cuando no puede descartarse que la administración de los centros mineros de El Abra y Collahuasi haya estado en manos de dirigentes locales incaizados, mientras que en el caso de Cerro Verde pudo tratarse de una autoridad más directamente relacionada con el estado. Evidentemente, los datos actuales no permiten fundamentar esta posibilidad.

Por otro lado, en el caso de que las operaciones extractivas estuvieran alejadas de las wakas mineras y de los centros provinciales, se debió implementar una infraestructura más elaborada que incluía una red de senderos troperos y sitios de enlace, así como una serie de campamentos satélites que cumplían funciones de apoyo a los centros productivos. Lo anterior fue imprescindible en sectores como El Abra y Collahuasi donde no había nodos de población local cercanos a las instalaciones mineras. En los campamentos mineros se empleó arquitectura incaica en las bodegas y las estructuras de preparación comunal de alimentos, remarcando materialmente la generosidad del estado en el marco de relaciones de reciprocidad. Y, por último, se habilitaron estructuras de carácter ceremonial de escala pequeña comparadas con los centros provinciales, pero en las cuales se habrían desarrollado rituales con un cierto grado de control estatal con el objeto de propiciar a las wakas locales de los yacimientos mineros.

A partir de lo anterior es posible postular la existencia de diferentes jerarquías entre las wakas mineras de la región. Las más importantes serían las qaqas junto a las cuales se instalaron los centros provinciales incaicos, las cuales a su vez se asocian a importantes cerros tales como el Miño, el Cerro Colorado y los cerros tutelares del río Salado (Paniri, León y Cablor-Chita). Secundarias a éstas estarían las wakas locales de los sitios de producción mineros, que serían posiblemente los cerros más altos de la localidad donde se explotan los minerales (Cerro Pajonal y Cerro Las Marías en El Abra y, eventualmente, 
Cerro Pabellón del Inca en Collahuasi y Cerro Verde en la localidad homónima).

Por último, nos parece relevante concluir señalando que la existencia de dos modelos de organización socioespacial de la producción minero-metalúrgica en Atacama y el altiplano sur de Tarapacá es coherente con la conocida afirmación de que la expansión y administración incaica de las provincias no tuvo un carácter homogéneo sino que presentó un conjunto flexible de estrategias y sistemas de organización. Los datos discutidos en este trabajo sugieren que dicha diversidad se generó incluso al interior de un mismo territorio étnico, y que respondió a la forma particular en que las autoridades estatales articularon variables productivas, sociopolíticas, económicas y simbólicas, con el objeto de asegurar una producción excedentaria de minerales de cobre que abasteciera la demanda de la religión y la economía política del Tawantinsuyu.
Agradecimientos: La presente investigación ha sido financiada por los Proyectos Fondecyt 1100905 y el Proyecto Arqueológico El Abra. Quisiéramos agradecer muy especialmente a los equipos de terreno y laboratorio de ambos proyectos, por su importante contribución al desarrollo de nuestra investigación. Asimismo, agradecemos a Paulina Chávez por la Figura 1, Rolando Ajata por la Figura 2 y Héctor Orellana por la Figura 5. El presente artículo se vio enriquecido gracias al taller realizado en el área de estudio por los dos autores principales de este artículo en conjunto con los colegas Carlos Angiorama y Axel Nielsen, en el marco del proyecto de Cooperación Internacional del Fondecyt antes referido. Agradecemos también a tres evaluadores anónimos por sus aportes y comentarios. Evidentemente, la responsabilidad por lo planteado en el artículo es exclusivamente de los autores.

\section{Referencias Citadas}

Absi, P. 2003. Les Ministres du Diable. Le Travail et ses Représentations dans les Mines de Potosí. Editions L'Harmattan, Paris.

Acuto, F. 1999. Paisaje y dominación, la constitución del espacio social en el Imperio Inca. En Sed non Satiata. Teoría Social en la Arqueología Latinoamericana Contemporánea, editado por A. Zarankin y F. Acuto, pp. 33-77. Ediciones del Tridente, Buenos Aires.

- - - 2012. Landscapes of inequality, spectacle and control: Inka social order in provincial contexts. Revista Chilena de Antropología 25:9-64.

Adán, L. 1999. Aquellos antiguos edificios. Acercamiento arqueológico. Estudios Atacameños 18:13-33.

Adán, L. y M. Uribe 2005. El dominio inca en la localidad de Caspana: Un acercamiento al pensamiento político andino (Río Loa), norte de Chile. Estudios Atacameños 29:41-66.

Aldunate, C. y V. Castro 1981. Las Chullpas de Toconce y su Relación con el Poblamiento Altiplánico en el Loa Superior, Período Tardío. Editorial Kultrún, Santiago.

Aldunate, C., V. Castro y V. Varela 2006. San Bartolo. Retazos de una historia de la minería en Atacama. Actas del XVII Congreso Nacional de Arqueología Chilena, pp. 213-225. Tomé.

- - - 2008. San Bartolo y Cobija: Testimonios de un modo de vida minero en las tierras altas y la costa de Atacama. Estudios Atacameños 35:97-117.

Angiorama, C. 2001. De metales, minerales y yacimientos. Contribución al estudio de la metalurgia prehispánica en el extremo noroccidental de Argentina. Estudios Atacameños 21:63-87.
- - - 2007. ¿Una ofrenda "caravanera” en Los Amarillos? Minerales y tráfico de bienes en tiempos prehispánicos. En Producción y Circulación Prehispánicas de Bienes en el Sur Andino, editado por A.E. Nielsen, M.C. Rivolta, V. Seldes, M.M. Vásquez \& P. H. Mercolli, pp. 383-392. Editorial Brujas, Córdoba.

Ballard, C. y G. Banks 2003. Resource wars: the anthropology of mining. Annual Review of Anthropology 32: 287-313.

Bell, P. 1998. The fabric and structure of Australian mining settlements. En Social Approaches to an Industrial Past, editado por B. Knapp, V. Pigott y J. Herbert, pp. 27-38. Routledge, London y New York.

Berenguer, J. 2004. Caravanas, Interacción y Cambio en el Desierto de Atacama. Sirawi Ediciones, Santiago.

- - - 2007. El camino inka del Alto Loa y la creación del espacio provincial en Atacama. En Producción y Circulación Prehispánicas de Bienes en el sur Andino, editado por A.E. Nielsen, M.C. Rivolta, V. Seldes, M.M. Vásquez y P. H. Mercolli, pp. 413-443. Editorial Brujas, Córdoba.

- - - 2010. Estrategias ocupacionales incaicas en dos espacios internodales del norte de Chile. Actas del XVII Congreso Nacional de Arqueología Chilena, Vol. 2, pp. 1389-1401. Ediciones Kultrún, Valdivia.

Berenguer, J., I. Cáceres, C. Sanhueza y P. Hernández. 2005. El Qhapaqnan en el Alto Loa, norte de Chile: un estudio micro y macromorfológico. Estudios Atacameños 29:7-39.

Berenguer, J., C. Sanhueza y I. Cáceres 2011a. Diagonales incaicas, interacción interregional y dominación en el altiplano de Tarapacá, norte de Chile. En En Ruta, Arqueología, Historia y Etnografía del Tráfico sur Andino, editado por L. Núñez y A. Nielsen, pp. 247-283. Encuentro Grupo Editor, Córdoba. 
- - - 2011b. Primer reporte de investigación sobre asentamientos incaicos en el distrito de Miño-Collahuasi: Excavaciones en Miño-2, Alto Loa, Región de Antofagasta. Informe Primer Año Proyecto Fondecyt 1000905. Manuscrito en posesión de los autores.

Bird, J. 1979. The copper man: A prehistoric miner and his tools from northern Chile. En Precolumbian metallurgy of South America, editado por E. Benson, pp. 105-131. Dumbarton Oaks Research Library and Collection, Washington D.C.

Bouysse-Cassagne, T. 2004. El sol de adentro: Huacas y santos en las minas de Charcas y en el lago Titicaca (siglos XV a XVII). Boletín de Arqueología PUCP 8:59-97.

- - - 2008. Minas del sol, del Inka, y de la gente. Potosí en el contexto de la minería prehispana. En Minas y Metalurgias en los Andes del Sur, entre la Época Prehispánica y el Siglo XVII, editado por P. Cruz y J. Vacher, pp. 278-301. Instituto Francés de Estudios Andinos e Institut de Recherche pour le Développement (IRD), Sucre.

Camus, F. 2003. Geología de los Sistemas Porfíricos en los Andes de Chile. Servicio Nacional de Geología y Minería, Santiago de Chile.

Cantarutti, G. 2012. Mining under inca rule in north-central Chile: The Los Infieles mining complex. En Mining and Quarrying in the Ancient Andes: Sociopolitical, Economic and Symbolic Dimensions, editado por K. Vaughn and N. Tripevich, pp. 185211. Springer, New York, en prensa.

Castro, V. 1992. Nuevos registros de la presencia Inka en la Provincia de El Loa, Chile. Gaceta Arqueológica Andina VI (21):139-154.

Castro V. y C. Aldunate 2003. Sacred mountains in the highlands of the South Central Andes. Mountain Research and Development 23:73-79.

Cervellino, M. y F. Téllez. 1980. Emergencia y desarrollo de una aldea prehispánica de Quillagua, Antofagasta. Contribución Arqueológica 1:1-235.

Cornejo, L. 1995. El Inka en la Región del río Loa: lo local y lo foráneo. Actas del XIII Congreso Nacional de Arqueología Chilena, pp. 203-212. Universidad de Antofagasta, Antofagasta.

Costin, C. 2001. Craft Production Systems. En Archaeology at the Millennium, editado por G. Feinman and T. Douglas Price, pp. 273-327. Kluwer, New York.

Cruz, P. 2006. Mundos permeables y espacios peligrosos. Consideraciones acerca de punkus y qaqas en el paisaje altoandino de Potosí, Bolivia. Boletín del Museo Chileno de Arte Precolombino 11:35-50.

- - - 2009. Huacas olvidadas y cerros santos. Apuntes metodológicos sobre la cartografía sagrada en los Andes del sur de Bolivia. Estudios Atacameños 38:55-74.

Dean, C. 2010. A culture of stone. Inka perspectives on rock. Duke University Press.

Eliade, M. 1974. Herreros y alquimistas. Alianza Editorial, Madrid.

Farrington, I. 1999. El Shincal: Un Cusco del Kollasuyu. Actas del XII Congreso Nacional de Arqueología Argentina, tomo I: 53-62. La Plata.
Figueroa, V., I. Montero y S. Rovira 2010. Estudio tecnológico de objetos de cobre procedentes de Cerro Turquesa (San José del Abra, II Región). Actas del XVII Congreso Nacional de Arqueología Chilena, tomo II, pp. 1135-1147. Ediciones Kultrún, Valdivia.

Figueroa, V., D. Salazar, H. Salinas, P. Núñez-Regueiro y G. Manríquez 2012. Pre-hispanic mining ergology of northern Chile: an archaeological perspective. Chungara Revista de Antropología Chilena 45:61-81.

García-Albarido, F. 2007. Umiñas en el Tawantinsuyo e Intermedio Tardío de Atacama: aproximación a la lapidaria en la vertiente occidental de la subárea circumpuneña. Informe de Práctica Profesional. Universidad de Chile. Manuscrito en posesión del autor.

González C. y C. Westfall 2005. Consideraciones sobre la prehistoria de Atacama: El Salvador y sus aportes locales e interregionales. Boletín Sociedad Chilena de Arqueología 38:53-70.

Hermosilla, N. y M. Barrera 2010. Calama, antiguos habitantes del oasis. Actas del XVII Congreso Nacional de Arqueología Chilena, Vol. 1, pp. 107-117. Ediciones Kultrún, Valdivia.

Hyslop, J. 1990. Inka Settlement Planning. University of Texas Press, Austin.

Knapp, B. 1998. Social approaches to the archaeology and anthropology of mining. En Social Approaches to an Industrial Past. The Archaeology and Anthropology of Mining, editado por B. Knapp, V. Piggott y J. Hubert, pp. 1-24. Routledge, Londres.

- - - 1999. Ideational and industrial landscape on prehistoric Cyprus. En Archaeologies of Landscape, Contemporary Perspectives, editado por W. Ashmore y B. Knapp, pp. 229-252. Blackwell, Oxford.

Llagostera, A. 1976. Hipótesis sobre la expansión incaica en la vertiente occidental de los Andes meridionales. En Homenaje al Dr. R. P. Gustavo Le Paige, editado por L. Núñez, pp. 203-218. Universidad del Norte, Antofagasta.

Lynch, T.F. y L. Núñez 1994. Nuevas evidencias inkas entre Kollahuasi y Río Frío (I y II Regiones del Norte de Chile). Estudios Atacameños 11:145-164.

Nielsen, A. 2003. Por las rutas del Zenta: evidencias directas de tráfico prehispánico entre Humahuaca y las Yungas. En La Mitad Verde del Mundo Andino, editado por B. Ortiz y B. Ventura, pp. 261-283. Universidad Nacional de Jujuy, Argentina.

Nielsen, A. y W. Walker 1999. Conquista ritual y dominación política en el Tawantinsuyo: El caso de Los Amarillos (Jujuy, Argentina). En Sed non Satiata: Teoría Social en la Arqueología Latinoamericana Contemporánea, editado por A. Zarankin y F. Acuto, pp. 153-169.Ediciones del Tridente, Buenos Aires.

Niemeyer, H. 1986. La ocupación incaica de la cuenca alta del río Copiapó (III región de Atacama, Chile). Comechingonia Número Especial: 165-294.

Niemeyer, H. y V. Schiappacasse 1998 [1987]. Patrones de asentamiento incaicos en el Norte Grande de Chile. En La Frontera del Estado Inca, editado por T. Dillehay y P. Netherly, pp. 114-152. Fundación Alexander von Humboldt / Editorial Abya-Yala, Quito. 
Núñez, L. 1987. Tráfico de Metales en el Área Centro-sur Andina: Factos y Expectativas. Cuadernos del Instituto Nacional de Antropología 12, Argentina.

- - - 1999. Valoración minero-metalúrgica circumpuneña: menas y mineros para el Inka Rey. Estudios Atacameños 18: $177-221$.

- - - 2006. La orientación minero-metalúrgica de la producción atacameña y sus relaciones fronterizas. En Esferas de Interacción Prehistóricas y Fronteras Nacionales Modernas: Los Andes Surcentrales, editado por H. Lechtman, pp. 205-260. IEP-IAR, Lima.

Núñez L., C. Agüero, B. Cases y P. de Souza 2003. El campamento minero Chuquicamata-2 y la explotación cuprífera prehispánica en el desierto de Atacama. Estudios Atacameños 25: 7-34.

Núñez, L., M. Grosjean e I. Cartajena 2005. The expansion of the Inka empire into the Atacama Desert. En $23^{\circ} \mathrm{S}$ : Archaeology and Environmental History of the Southern Deserts, editado por M. Smith y P. Hesse, pp. 324-332. National Museum of Australia Press, Canberra.

Oyarzún, J. 2000. Andean metallogenesis: a synoptical review and interpretation. En Tectonic Evolution of South America, editado por U.G. Cordani, E.J. Milani, A. Thomas Filho y D.A Campos, pp. 725-753. Proceedings of the IUGS Conference, Rio de Janeiro.

Platt, T. y P. Quisbert 2008. Sobre las huellas del silencio: Potosí, los incas y el virrey Francisco de Toledo (siglo XVI). En Minas y Metalurgias en los Andes del Sur, entre la Época Prehispánica y el Siglo XVII, editado por P. Cruz y J. Vacher, pp. 231-277. Instituto Francés de Estudios Andinos e Institut de Recherche pour le Développement (IRD), Sucre.

Raffino, R. 1981. Los Inkas del Kollasuyu. Ramos Americana Editora, La Plata.

Rees, Ch. 1999. Elaboración, distribución y consumo de cuentas de malaquita y crisocola durante el Período Formativo en la vega de Turi y sus inmediaciones, subregión del río Salado, norte de Chile. En Los Tres Reinos: Prácticas de Recolección en el Cono Sur de América, editado por C. Aschero, A. Korstanje y P. Vuoto, pp. 85-98. Instituto de Arqueología y Museo, Universidad Nacional de Tucumán, Tucumán.

Rodríguez, L. 1981. La Production Métallurgique dans les Sociétés Précolombines des Andes Meridionales. Tesis Doctoral, Ecole de Hautes Etudes en Sciences Sociales, París, Francia.

Romero, Á. y L. Briones 1999. Co-37: Estado y planificación inca en Collahuasi (Provincia de Iquique, I región, Chile). Estudios Atacameños 18:141-14.

Salazar, D. 2002. El Complejo Minero San José del Abra, II región (1450-1536 d.C.): Una Aproximación a la Arqueología de la Minería. Tesis para optar al grado de Magíster en Arqueología, Universidad de Chile, Santiago.

- - - 2003-2004. Arqueología de la minería: Propuesta de un marco teórico. Revista Chilena de Antropología 17:125-149.

- - - 2002-2005. Investigaciones arqueológicas sobre la minería incaica en San José del Abra (II región, norte de Chile). Xama 15-18:101-118.
- - - 2008. La organización de la producción minera en San José del Abra durante el Período Tardío Atacameño. Estudios Atacameños 36:43-72.

Salazar D. y H. Salinas 2008. Tradición y transformaciones en la organización de los sistemas de producción mineros en el norte de Chile prehispánico: San José del Abra, siglos I al XVI d.C. En Mina y Metalurgia en los Andes del Sur desde la Época Prehispánica hasta el Siglo XVII, editado por P. Cruz y J-J Vacher, pp. 163-200. Instituto Francés de Estudios Andinos, Sucre.

Salazar, D., H. Salinas, V. McRostie, R. Labarca y G. Vega 2010. Cerro Turquesa: Diez siglos de producción minera en el extremo norte de Chile. Actas del XVII Congreso Nacional de Arqueología Chilena, Tomo II, pp. 1085-1097. Ediciones Kultrún, Valdivia.

Salazar, D., V. Castro, J. Michelow, H. Salinas, V. Figueroa y B. Mille 2010. Minería y metalurgia en la costa arrecia de la región de Antofagasta, norte de Chile. Boletín del Museo Chileno de Arte Precolombino 15: 9-23.

Salazar, D., J. Berenguer, H. Carrión y H. Orellana 2011. Informe minero-metalúrgico: prospecciones, excavaciones y análisis. Informe Primer Año Proyecto Fondecyt 1000905. Manuscrito en posesión de los autores.

Salazar, D., C. Borie y C. Oñate 2012. Mining, commensal politics and ritual under Inka rule in Atacama, northern Chile. En Mining and Quarrying in the Ancient Andes: Sociopolitical, Economic and Symbolic Dimensions, editado por N. Tripcevich y K. Vaughn, pp. 253-274. Springer, New York, en prensa.

Salazar-Soler, C. 2002. Anthropologie des Mineurs des Andes. Dans les Entrailles de la Terre. L'Harmattan, Paris.

Salinas, H. y D. Salazar 2008. Cadenas operativas y sistemas de explotación minera prehispánica. En Puentes hacia el Pasado: Reflexiones Teóricas en Arqueología, editado por D. Jackson, D. Salazar y A. Troncoso, pp. 73-92. Serie Monográfica de la Sociedad Chilena de Arqueología 1, Santiago.

Sepúlveda, M. y E. Laval 2010. Uso de minerales de cobre en la pintura rupestre de la localidad de río Salado (II región, norte de Chile). Actas del XVII Congreso Nacional de Arqueología Chilena, Tomo II, pp. 1111-1122. Ediciones Kultrún, Valdivia.

Shimada, I. 1994. Pre-Hispanic metallurgy and mining in the Andes: recent advances and future tasks. En In Quest of Mineral Wealth: Aboriginal and Colonial Mining and Metallurgy in Spanish America, editado por A. Craig y R. West, Vol. 33, pp. 37-73. Baton Rouge, Geoscience and Man, Louisiana.

Shimada. I., A. Bexur, D. Goldstein y U. Wagner 2007. Sicán metalworkings furnaces: Excavation, archaeometric, and experimental data and insights into their operation and broader production context. En Metalurgia en la América Andina, editado por R. Llleras. Banco de la República / IFEA, Bogotá.

Soto, C. 2010. Tipología de cuentas de collar en la Quebrada de Tulán (Salar de Atacama): Nueva línea de evidencia para la transición Arcaico-Formativo. Actas del XVII Congreso Nacional de Arqueología Chilena, Tomo II, pp. 1123-1134. Ediciones Kultrún, Valdivia.

Upham, S. 1992. Interaction and isolation: The empty spaces in panregional political and economic systems. En Resources, power, and interregional interaction, editado por E.M. Schortman y P.A. Urban, pp. 139-152. Plenum Press, New York. 
Urbina, S. y C. González 2004. Asentamientos tardíos en el Camino Inka del Alto Loa: análisis arquitectónico de las instalaciones en el tramo Lasana-Miño. Informe interno Proyecto Fondecyt 1010327. Manuscrito en posesión de los autores.

Uribe, M. y G. Cabello 2005. Cerámica en el camino: los materiales del río Loa (Norte Grande de Chile) y sus implicancias tipológicas y conductuales para la comprensión de la vialidad y la expansión del Tawantinsuyo. Revista Española de Antropología Americana 33:75-98.

Uribe, M. y C. Carrasco 1999. Tiestos y piedras talladas de Caspana: la producción alfarera y lítica en el Período Tardío del Loa Superior. Estudios Atacameños 18:55-87.

Uribe, M. y S. Urbina 2009. Cerámica y arquitectura pública en el Camino del Inka del Desierto de Atacama (río Loa, Norte de Chile). Revista Chilena de Antropología 20:227-260. van Kessel, J. 1989. Ritual de producción y discurso tecnológico. Chungara 23:73-91.

Westfall, C. y C. González 2010. Mina Las Turquesas: Un Asentamiento Minero Lapidario Preincaico en el Extremo Meridional Circumpuneño, Región de Atacama, Chile. Actas del XVII Congreso Nacional de Arqueología Chilena, Tomo II, pp. 1073-1082. Ediciones Kultrún, Valdivia.

Zori, C. 2011. Metals for the Inka: Craft Production and Empire in the Quebrada de Tarapacá, Northern Chile. Tesis Doctoral. University of California Los Angeles, California.

Zori, C. y P. Tropper 2010. Late pre-hispanic and early colonial silver production in the Quebrada de Tarapacá, Northern Chile. Boletín del Museo Chileno de Arte Precolombino 15:65-87.

\section{Notas}

1 Proyecto FONDECYT 1100905.

2 Por el momento no conocemos evidencias directas de minería en Tarapacá, a excepción de los martillos de Huantajaya, en la Cordillera costera junto a Iquique. Las fechas Intermedio Tardío (entre otras del período Tardío) obtenidas por uno de nosotros en el campamento de Yabricoyita (sitio CO-37), en Collahuasi (Berenguer et al. 2011a), parecen indicar una actividad minera preincaica en el sector, pero por el momento no es posible afirmarlo.

3 La del Talikuna con el Curte por el sur y la del Curte con el Caspana por el norte.

4 Aun cuando las investigaciones recientes apenas hacen alusión a este campamento, Rodríguez (1981) sí lo describe en su tesis doctoral, identificando correctamente su ubicación y características generales y presentando un croquis del sitio.
5 Se trata de "un cerro que aloja un cuerpo de arenas claras y otro de arenas oscuras, que se mueven y emiten sonido con el viento; se trata de un rasgo natural que se divisa desde mucha distancia y que fue y sigue siendo objeto de actividad ritual y motivo de varias leyendas entre la población local" (Berenguer 2007: 423).

6 Sitios como Turi, o Catarpe en el Salar de Atacama, comparten algunas de estas características, pero no el hecho de que fueron construidos por los Incas en lugares sin ocupaciones previas del Intermedio Tardío. Posiblemente un cuarto centro provincial incaico en Atacama, comparable a los aquí descritos, sea el denominado Tambo de Licancabur.

7 Para el caso de Cerro Verde no es posible asegurarlo por la mala calidad de la muestra. 
